NBER WORKING PAPER SERIES

\title{
RURAL-URBAN MIGRATION, STRUCTURAL TRANSFORMATION, AND HOUSING MARKETS IN CHINA
}

\author{
Carlos Garriga \\ Aaron Hedlund \\ Yang Tang \\ Ping Wang \\ Working Paper 23819 \\ http://www.nber.org/papers/w23819 \\ NATIONAL BUREAU OF ECONOMIC RESEARCH \\ 1050 Massachusetts Avenue \\ Cambridge, MA 02138 \\ September 2017
}

The authors are grateful for stimulating discussions with Costas Azariadis, Rick Bond, James Bullard, Kaiji Chen, Morris Davis, Jang-Ting Guo, Berthold Herrendorf, Tom Holmes, Alexander Monge-Naranjo, Yongs Shin, Don Schlagenhauf, B. Ravikumar, Paul Romer, Michael Spence, Stijn Van Nieuwerburgh, Yi Wen, and the seminar participants at the Federal Reserve Bank of St. Louis, Fengchia University, Nanyang Technological University, National Chengchi University, National Taiwan University, National University of Singapore, Washington University in St. Louis, the China Economics Summer Institute, the Econometric Society Asia Meeting, the International Real Estate Conference in Singapore, the Midwest Economic Association Meeting, the Society for Economic Dynamics Meeting, the NBER conference on the Chinese Economy, the Shanghai Macroeconomic Workshop, and the Society for the Advancement of Economic Theory Meeting. The views expressed herein do not necessarily reflect those of the Federal Reserve Bank of St. Louis, the Board of Governors, or the Federal Reserve System. The views expressed herein are those of the authors and do not necessarily reflect the views of the National Bureau of Economic Research.

NBER working papers are circulated for discussion and comment purposes. They have not been peer-reviewed or been subject to the review by the NBER Board of Directors that accompanies official NBER publications.

(C) 2017 by Carlos Garriga, Aaron Hedlund, Yang Tang, and Ping Wang. All rights reserved. Short sections of text, not to exceed two paragraphs, may be quoted without explicit permission provided that full credit, including $(\odot$ notice, is given to the source. 
Rural-Urban Migration, Structural Transformation, and Housing Markets in China

Carlos Garriga, Aaron Hedlund, Yang Tang, and Ping Wang

NBER Working Paper No. 23819

September 2017

JEL No. E20,O41,R21,R31

\section{$\underline{\text { ABSTRACT }}$}

This paper explores the contribution of the structural transformation and urbanization process to China's housing-market boom. Rural to urban migration together with regulated land supplies and developer entry restrictions can raise housing prices. This issue is examined using a multi-sector dynamic general-equilibrium model with migration and housing. Our quantitative findings suggest that this process accounts for about 80 percent of urban housing price changes. This mechanism remains valid in extensions calibrated to the two largest cities with most noticeable housing booms and to several alternative setups. Overall, supply factors and productivity account for most of the housing price growth.

\author{
Carlos Garriga \\ Federal Reserve Bank of St. Louis \\ P.O. Box 442 \\ St. Louis, MO 63166 \\ carlos.garriga@stls.frb.org \\ Aaron Hedlund \\ University of Missouri \\ 118 Professional Building \\ Columbia, MO 65211 \\ hedlunda@missouri.edu
}

\author{
Yang Tang \\ Nanyang Technological University \\ 50 Nanyang Avenue, Singapore 639798 \\ tangyang@ntu.edu.sg
}

Ping Wang

Department of Economics

Washington University in St. Louis

Campus Box 1208

One Brookings Drive

St. Louis, MO 63130-4899

and NBER

pingwang@wustl.edu 


\section{Introduction}

Over the past three decades, several major developed and developing economies have experienced sizable housing booms over prolonged periods. China - the world's factory - is one of the most prominent cases of rapid growth. It has experienced a fast but still ongoing structural transformation from a largely agricultural society to a modern one whose agricultural employment share was reduced from almost 70 percent in 1980 to about 33 percent in 2012 . Compared with the speed of its structural transformation, China's urbanization process has been relatively moderate, with the rural population dropping from about three-quarters to still more than half over the same period. Given this moderate urbanization pace, it is to some degree puzzling why China has experienced one of the most noticeable price hike's in urban housing markets, leading its government to implement regulatory mortgage and sales policies to cool off the housing market even shortly after the financial tsunami. ${ }^{1}$ The primary purpose of this paper is to investigate this issue by exploring the role structural transformation played in China's housing boom.

We highlight three major channels through which structural change may have affected housing prices. First, structural transformation increases manufacturing productivity and that generates higher incomes in urban areas and a greater ability to pay for housing. Second, the housing supply is relatively inelastic due to heavy regulations on land supply and the market entrance of real estate developers. As a consequence of structural transformation, the third channel is an ongoing rural-urban migration that increases the demand for urban housing. Our view is that structural transformation implies job reallocation from agricultural to non-agricultural sectors and also induces migration from rural to urban areas where most production takes place.

The appreciation of housing values has been remarkable in China. Figure 1 shows the average real housing price per square meter in China has increased rapidly from about 750 RMB in 1998 to $5000 \mathrm{RMB}$ in 2012. To motivate the main mechanism in our paper, we further report cross-city data of structural transformation, migration flows, and housing prices in Figure 2. The top panel plots the average annual growth rate of housing prices against the average annual growth rate of net migration from rural areas to China's 29 major cities from 1998-2007. ${ }^{2}$ The positive relationship suggests that housing prices grow faster in cities with larger net inflows of migrants from rural areas. The bottom panel plots the average annual

\footnotetext{
${ }^{1}$ Based on the 2000 census, about 87 percent of Chinese households owned houses. According to the National Bureau of Statistics of China, the total residential investment in urban areas reached nearly 57.8 trillion RMB in 2012, which is 100 times more than it was in 1998. The rising demands have led to a surge in housing prices (as documented below). The processes of China's structural transformation and urbanization and its migration policies and the deregulation of housing markets are summarized in Appendix A.

${ }^{2}$ This list includes all the first-tier and major second-tier cities in China.
} 
growth rate of the employment share in the non-agricultural sector against the average annual growth rate of migration from rural areas to the 29 cities. The positive relationship implies most migrants from rural areas work in the non-agricultural sector in the cities. These two observations together are consistent with the idea that workers migrating from rural areas to cities most likely have switched from agricultural to non-agricultural jobs. As such, cities offering more non-agricultural jobs can potentially attract more migrants, which in turn can lead to faster housing price growth.

In order to fully examine the influence of structural transformation on urban housing development, we construct a dynamic general equilibrium model with structural transformation and endogenous migration. Specifically, we consider an economy that is geographically divided into two regions: a rural area that produces agricultural goods and an urban area (city) that produces manufactured goods (inclusive of urban services in the remainder of the paper). Ongoing technological progress drives workers away from the rural agricultural sector to the urban manufacturing sector. In the baseline model, we assume that workers arriving in a city must purchase a house with a down payment and a long-term mortgage and that, while a house is required for urban living, it has no resale value. New homes are built by real estate developers who purchase land and construction permits from the government.

Our basic framework considers only a single urban area and then it is generalized to multiple cities. This extension allows us to assess the contribution of different migration flows to changes in housing price growth rates across cities. More importantly, evaluating what contributed to the structural transformation of large cities further allows us to determine whether or not any portion of the noticeable appreciation in housing prices is induced by structural change.

To disentangle the contributions of various underlying forces (housing finance, entry restrictions, land supply policy, and the productivity of the manufacturing sector), we calibrate the model to mimic the early stages of development in China from 1980 to 2012. The future projected path for China's structural transformation through 2065 is based on the U.S. experience from 1950 to 1990. We restrict our attention to the period from 1998 to 2012. This is because China's pre-1998 housing market was largely controlled by the government and housing prices were heavily regulated.

The main findings can be summarized as follows. At the national level, the process of structural change can account for 80.5 percent of housing over 1998-2012 and 86.1 percent over 1998-2007 prior to financial tsunami and the subsequent housing regulations. More specifically, supply factors account for more than 60 percent of the changes in housing prices. Productivity (income) accounts for more than one-fifth of the changes in housing with its contribution rising over time, while access to credit has limited impact throughout the entire 
sample period.

In the multiple-city case, the model accounts for 82.8 percent and 60.2 percent of housing price growth in Beijing and Shanghai, respectively. While supply conditions remain crucial, productivity growth becomes more important in explaining Shanghai's housing prices. In both cities, the role played by productivity is enhanced during 2008-2012. This finding suggests that market fundamentals driven by structural transformation remain a key driver of housing prices. ${ }^{3}$

The baseline model is then extended in several dimensions, including the smoothness of the volatile migration flows, the consideration of tenant-occupied housing, the adoption of non-homothetic preferences, the introduction of housing quality and the incorporation of savings, the consumption valuation of housing, and the investment value of housing. We find that while these extensions could improve on the predictability of housing price movements in China, such improvements are either marginal or moderate. Thus, not only does structural transformation remain an important driver of China's housing boom, but our baseline model can also be viewed as an adequate benchmark for the purpose of our study.

In summary, by incorporating endogenous rural-urban migration decisions responding to structural change, we find that the process of relocating workers to cities together with regulated land supplies and developer entry restrictions can account for a major portion of the housing boom in China.

\section{Literature Review}

The Chinese economy has undergone many political and economic reforms since 1978. Its rapid growth has made it the second-largest economy in the world, with especially significant growth since 1992. There is a large literature studying the development of China. For brevity, the reader is referred to Zhu (2012) for an extensive summary of the various stages of economic development. There is a small but growing literature investigating China's housing boom, including research by Chen and Wen (2014), Fang, Gu and Zhou (2014), and Deng, Gyourko, and $\mathrm{Wu}$ (2015). In contrast to this literature, we highlight the structural transformation of the manufacturing sector as a key driver of rural migrants to the cities. There have been numerous studies on structural transformation using dynamic general equilibrium models without spatial considerations. For a comprehensive survey, the reader is referred to Herrendorf, Rogerson, and Valentinyi (2014). Of particular relevance, Hansen and Prescott (2002) and Ngai and Pissaridis (2007) emphasize the role of different total factor productivity

\footnotetext{
${ }^{3}$ At the micro level, an issue that is frequently noted is the possibility of the burst of "ghost cities," referring to major urban property developments which have remained mostly unoccupied after they were built. It is noted, however, that this is not a widespread phenomenon and refers to third or lower-tier cities often overly built by the government. There is some speculation whether these cities may experience housing bubbles, but these are not representative of the major metropolitan areas in China.
} 
(TFP) growth rates played in the process of structural change. In our paper, the productivity gap between urban and rural areas is a main driver of ongoing rural-urban migration.

The literature of dynamic rural-urban migration is much smaller. While Glomm (1992) studies rural-urban migration as a result of higher urban productivity due to agglomerative economies, Lucas (2004) highlights a dynamic driver of such migration, the accumulation of human capital and hence the ongoing rise in city wages. More recently, Bond, Riezman, and Wang (2014) show that trade liberalization in capital-intensive import-competing sectors prior to China's accession to the WTO has accelerated the migration process and capital accumulation, leading to faster urbanization and economic growth. Tombe and Zhu (2015) find that reduction in internal trade and migration costs accounted for almost two-fifth of aggregate labor productivity growth in China over 2000-2005, even more important than international trade liberalization. Also focusing on China, Liao et al. (2014) find that education-based migration plays an equally important role with work-based migration in the process of urbanization. None of these papers study housing markets.

In our paper, migration increases the demand for residential housing and thus affects prices. To isolate the contribution of migration flows to housing prices, in the model, housing demand is determined only by migrants moving from rural areas to cities (the extensive margin). This formalization contrasts with a large literature using general equilibrium asset pricing frameworks (e.g., Davis and Heathcote, 2004), where prices are determined by a representative individual who adjusts the quantity of housing consumed. From the housing supply perspective, our model emphasizes the role of government restrictions on the production of housing units. By further incorporating limited access to the financial market for housing purchases, the analysis in our paper is connected to a large literature that explores financial frictions as drivers of housing boom-bust episodes (e.g., see papers cited by Garriga, Manuelli, and Peralta-Alva, 2012). In contrast to these housing papers, our paper focuses on the economic development angle with the migration decision endogenously determined in the model.

\section{The Model}

To suit the main purpose of the paper, we design a conservative benchmark that rule out bubbles by having housing as a necessity without secondary market trading. Under this baseline setting, there are no precautionary or speculative motives for housing investments. In the absence of any intensive margin (via quantity or quality of housing), all the action must be through the extensive margin via migration flows. Under this conservative benchmark, we evaluate how much structural transformation and the resulting rural-urban migration may 
account for the upward trend in housing price movements in China.

The baseline model has four key ingredients: The first and most important, is the structural transformation primarily driven by the productivity gap between the rural agricultural and the urban manufacturing sectors. This induces ongoing rural-urban migration and leads to higher demand for housing in urban areas. The second, also on the demand side, is mortgage institutions, particularly the down payment requirement that may limit potential buyers' access to the credit market. There are two additional ingredients on the supply side. One is the incremental land supply primarily controlled by the Chinese government. Another is the entry cost incurred by housing developers. These ingredients interact in a dynamic general equilibrium setting, affecting migration decisions and housing prices.

Our model encompasses both owning and renting housing using consol mortgage with a fractional down payment. Given the high homeownership rate in China (even in large cities), we assume a baseline model with owner-occupied housing. The pure rental case is analyzed in Section 4. Other important institutional features guide the modeling choice. In particular, given the low vacancy rate, we assume housing market clearance in equilibrium. Since land is owned and allocated by the local Chinese government, it is assumed that the land supply is exogenous.

The benchmark economy is geographically divided into two regions: a rural area and a city. Later the model is extended to the case of multiple cities. There are two types of goods produced in the two separate regions: The rural area produces agricultural goods and the city produces manufactured goods. In line with the structural transformation literature, both production processes depend on employment, which is better measured in the data for developing economies.

The agents are also classified into two categories: workers (agricultural or manufacturing) and housing developers. Agricultural workers live in the rural area and manufacturing workers live in the city. To switch from agricultural to manufacturing jobs, workers migrate to the city. The mass of workers is normalized to 1 . Workers are infinitely lived and each period they inelastically provide 1 unit of labor. All workers are identical in performing production activities. The only heterogeneity among workers stems from the level of disutility from migrating from the rural area to the city. The utility cost, $\epsilon$, follows a distribution function $F(\epsilon)$. Moving from the city back to a rural area is assumed to be costless. The interest rate for mortgage loans, $r^{*}$, is positive and exogenously determined. This determination is consistent with the interest rates in China being primarily controlled by the government.

In the following, we detail the different roles of rural workers, city workers, migrants, the government, and housing developers. The competitive spatial equilibrium is analyzed, and then the model is extended to allow rural agents to migrate to multiple cities. Again, to be 
on the conservative side, we omit small city to large city migration. We then generalize the model to permit durable housing investments and multiple units of housing.

\subsection{Rural Workers}

Workers in the rural area are self-employed, residing in their farm houses and producing agricultural goods. A single unit of labor can produce $A_{t}^{f}$ units of agricultural goods. Therefore, if there are $N_{t}^{f}$ workers in the rural area, the total supply of agricultural goods is

$$
f_{t}=A_{t}^{f} N_{t}^{f}
$$

Given the agricultural goods price, $p_{t}$, the income level of a rural worker is thus $p_{t} A_{t}^{f}$.

A worker derives utility from consumption of manufactured and agricultural goods. The bundle $\left(x_{t}^{m}, x_{t}^{f}\right)$ defines the amount of manufactured and agricultural goods consumed by rural workers. The recursive optimization problem for a rural worker in period $t$ can be written as follows:

$$
\begin{gathered}
V_{t}^{R}(\epsilon)=\max u\left(x_{t}^{f}, x_{t}^{m}\right)+\beta \max \left\{V_{t+1}^{R}(\epsilon), V_{t+1}^{M}(\epsilon)-\epsilon\right\}, \\
\text { s.t. } \quad p_{t} x_{t}^{f}+x_{t}^{m}=p_{t} A_{t}^{f},
\end{gathered}
$$

where $V_{t}^{R}(\epsilon)$ denotes the lifetime payoff for the rural worker in period $t$. The worker derives current utility level $u\left(x_{t}^{f}, x_{t}^{m}\right)$. In the next period, $t+1$, he can choose to either stay in the rural area or move to the city. The payoff associated to stay is represented by $V_{t+1}^{R}(\epsilon)$, and $V_{t+1}^{M}(\epsilon)$ is the payoff for a rural worker who moves to the city in period $t+1$ after paying the mobility cost, $\epsilon$, measured in terms of utility.

The population in the rural area is an equilibrium object and its determination is specified later. Since housing in the rural area is not relevant, we abstract from its formalization.

\subsection{City Workers}

Rural and city workers are assumed to share the same preference toward manufactured and agricultural goods. We assume that housing is a necessity for living in the city but does not provide utility. City workers gain utility from consuming manufactured and agricultural goods only when they own at least 1 unit of housing; otherwise, their utility levels are set at negative infinity. ${ }^{4}$ Specifically, $\left(c_{t}^{m}, c_{t}^{f}\right)$ denotes the amount of manufactured and agricultural goods consumed by city workers and $h_{t}$ denotes the number of housing units they own. A

\footnotetext{
${ }^{4}$ Workers must purchase a house on arrival in the city. For simplicity, the possibility of renting a house or purchasing one in the secondary market is not available. Otherwise, one would have to track distributions from renting and secondary market purchases, making the model intractable.
} 
city worker's instantaneous utility function takes the following form:

$$
U\left(c_{t}^{m}, c_{t}^{f}, h_{t}\right)=\left\{\begin{array}{ll}
u\left(c_{t}^{m}, c_{t}^{f}\right) & \text { if } h_{t} \geq 1 \\
-\infty & \text { otherwise }
\end{array},\right.
$$

where this utility function implies that each worker is satiated by owning 1 unit of housing and does not benefit from owning more. In equilibrium, manufacturing workers demand 1 unit of housing.

The optimization problem for workers who have already purchased a house in $\tau<t$ is

$$
\begin{gathered}
V_{t}^{C}\left(\epsilon, b_{\tau}\right)=\max U\left(c_{t}^{m}, c_{t}^{f}, h_{t}\right)+\beta \max \left\{V_{t+1}^{C}\left(\epsilon, b_{\tau}\right), V_{t+1}^{R}(\epsilon)\right\}, \\
\text { s.t. } \quad p_{t} c_{t}^{f}+c_{t}^{m}+b_{\tau} r^{*}=w_{t}^{m} .
\end{gathered}
$$

Workers who have been in the city for more than one period have two state variables: their utility cost from migration, $\epsilon$, and mortgage debt from purchasing a house at time $\tau, b_{\tau}$. Here, $V_{t}^{C}\left(\epsilon, b_{\tau}\right)$ represents the lifetime payoff for a worker with disutility level $\epsilon$ and mortgage

debt $b_{\tau}$. The worker derives current utility $U\left(c_{t}^{m}, c_{t}^{f}, h_{t}\right)$ and discounts future payoffs at rate $\beta$ by choosing between staying in the city, $V_{t+1}^{C}\left(\epsilon, b_{\tau}\right)$, or returning to the rural area, $V_{t+1}^{R}(\epsilon)$. The worker spends his wage income, $w_{t}^{m}$, on consumption of manufactured and agricultural goods and mortgage debt repayment, $b_{\tau} r^{*}$.

\subsection{Migration Decisions}

During the initial period $\tau$ when a rural worker moves to the city, he must purchase a house at price $q_{\tau}$. A house purchase is financed with an infinite consol fixed-rate mortgage and requires a down payment, which is an exogenous fraction $\phi$ of the housing price in the moving period $\tau$. In the following periods, the specified repayment is a constant $d_{\tau} . d_{\tau}$ can be derived by equating the size of the loan to the present discounted value of all mortgage payments:

$$
(1-\phi) q_{\tau} h_{\tau}=\sum_{t=\tau+1}^{\infty} \frac{d_{\tau}}{\left(1+r^{*}\right)^{t-\tau}}
$$

Given the constant interest rate, $r^{*}$, the constant payment is simply

$$
d_{\tau}=(1-\phi) r^{*} q_{\tau} h_{\tau}
$$

The mortgage contract satisfies

$$
\phi>\frac{r^{*}}{1+r^{*}} .
$$

This condition ensures that the down payment exceeds the mortgage payment each period. Notably, one may consider a city economy with all workers renting houses from absentee 
landlords who purchase them in advance to fill the demand. Maintaining the same housing demand structure, one may then capture this pure rental case by setting $\phi=r^{*} /\left(1+r^{*}\right)$, under which an agent migrating in period $\tau$ signs a long-term rental agreement paying a rent $d_{\tau}$ every period based on the housing price. ${ }^{5}$ Thus, the pure rental market can be viewed as a special case of our model (this case is discussed in more detail in Section 4.2). As elaborated in Section 4, abstracting from the rental market in this model gives a conservative prediction of the changes in housing prices.

The optimization problem of rural workers who move to the city in period $\tau$ is represented by

$$
\begin{gathered}
V_{\tau}^{M}(\epsilon)=\max U\left(c_{\tau}^{m}, c_{\tau}^{f}, h_{\tau}\right)+\beta \max \left\{V_{t+1}^{C}\left(\epsilon, b_{\tau}\right), V_{t+1}^{R}(\epsilon)\right\}, \\
\text { s.t. } \quad c_{\tau}^{m}+p_{\tau} c_{\tau}^{f}+q_{\tau} h_{\tau}=w_{\tau}^{m}+b_{\tau}, \\
b_{\tau} \leq(1-\phi) q_{\tau} h_{\tau} .
\end{gathered}
$$

The optimization problem is subject to a traditional budget constraint that the migration stage includes a down payment, the purchase of goods, and a borrowing constraint associated with mortgage financing. ${ }^{6}$ In Appendix B, we prove that an infinite consol fixed-rate mortgage has zero amortization and that, in the case of no reverse migration, the borrowing constraint must always be binding. ${ }^{7}$

Given the expressions for $V_{\tau}^{M}(\epsilon)$, and $V_{\tau}^{R}(\epsilon)$, we can determine the conditions under which workers with mobility cost $\epsilon$ move into the city at time $\tau$ as follows:

$$
V_{\tau}^{M}(\epsilon)-\epsilon \geq V_{\tau}^{R}(\epsilon)
$$

Workers will migrate to the city if and only if the payoff from migration is greater than from staying in the rural area. There exists an $\epsilon_{\tau}^{*}$ that solves $V_{\tau}^{M}\left(\epsilon_{\tau}^{*}\right)-V_{\tau}^{R}\left(\epsilon_{\tau}^{*}\right)=\epsilon_{\tau}^{*}$ and determines the cutoff level of rural workers who migrate to the city in any given period. As productivity in the city increases, the payoff associated with migration rises and the cutoff for the migration decision shifts to the right of the distribution $F(\epsilon)$. As a result, those workers

\footnotetext{
${ }^{5}$ Similar to the case of resales, allowing for a one-period rental agreement would make the model intractable because a migrant's decision would then depend on the entire path of current and future housing prices (and hence migration flows).

${ }^{6}$ We ignore the possibility that workers may default on the mortgage payment $d_{t}$. We can justify this argument by assuming workers are either perfectly committed or the punishment for default is severe. We do not exclude the possibility that a city worker may return to the rural area, but they would lose their down payment. Therefore, ideally, the situation that a relatively productive worker gives up his job in the city and returns to the rural area happens only when wages from working in the manufacturing sector are too low compared with those in the agricultural sector.

${ }^{7}$ When there is no reverse migration, the borrowing constraint will always be binding if the utility function is strictly increasing, weakly concave in the consumption component, and the discount factor satisfies $\beta \leq$ $\frac{1}{1+r^{*}}$. This assumption is realistic given the relatively low rate of reverse migration in China.
} 
initially unwilling to move now decide to migrate.

At the aggregate level, the incremental flow of migrants from the previous period is represented by

$$
\Delta F_{\tau}^{*}\left(\epsilon_{\tau}^{*}, \epsilon_{\tau-1}^{*}\right)=F\left(\epsilon_{\tau}^{*}\right)-F\left(\epsilon_{\tau-1}^{*}\right) .
$$

The flow of migrants is the key driver of housing prices in the model.

\subsection{Manufacturing Sector}

The manufactured goods market is perfectly competitive. For simplicity, labor is the only productive input abstracting from capital. In the quantitative analysis, increases in the capital-labor ratio would be included in productivity growth. The production technology of the manufacturing sector is linear in labor:

$$
Y_{t}^{m}=A_{t}^{m} N_{t}^{m}
$$

where $A_{t}^{m}$ denotes the labor productivity in the manufacturing sector at period $t$. The employment level in the city is endogenous and depends on the disutility cutoff for migration decisions, $N_{t}^{m}=F\left(\epsilon_{t}^{*}\right)$. The price of manufactured goods is normalized to 1 , and the optimality conditions imply

$$
w_{t}^{m}=A_{t}^{m}
$$

\subsection{Government}

In this economy land is owned and supplied by the government. Each period, the government determines the amount of land available for housing developers. The total land area in the city is normalized to 1 . The government decides to add $\ell_{t} \geq 0$ units of land for building houses at time $t$. The aggregate law of motion for land is represented by

$$
L_{t}=\ell_{t}+L_{t-1}
$$

where the aggregate land area occupied by houses in the city cannot exceed 1 ( i.e., $L_{t} \leq 1, \forall t$ ). Since the average house size is fixed, the law of motion for the housing stock is entirely characterized by the fraction of movers, $\Delta F_{t}^{*}$, and individuals in the city, $H_{t-1}$ :

$$
H_{t}=H_{t-1}+\Delta F_{t}^{*}
$$

where $H_{t-1}$ represents the number of houses that the government has granted permission to build up to in period $t$.

The government not only controls the supply of land but also charges a fee, $\Psi_{t}$, in units of 
manufactured goods, to housing developers, which determines the number of permits granted:

$$
\Psi_{t}=\psi H_{t-1},
$$

where the average land leasing fee, $\psi>0$, is constant over time. A larger number of permits granted in the past, $H_{t-1}$, implies a higher fixed construction fee. This assumption captures public concern about congestion and overcrowding in cities.

\subsection{Housing Developers}

Each housing developer is endowed with technology to convert land into houses. The production function takes a simple form as follows:

$$
h_{t}=A_{t}^{h} z_{t}^{\alpha}, \quad 0<\alpha<1
$$

The presence of decreasing returns to scale is necessary to allow for a developer to cover the fixed cost incurred from paying for a permit. Each housing developer is assumed to live for only one period and is replaced by an identical agent. This assumption, based on convenience, eliminates the complication of managing inventories of land. An incumbent developer needs to decide how much land to buy to maximize the operative profit $\Pi_{t}^{d}$. Upon receiving revenue from selling houses, the developer must pay a fixed cost to the government.

A representative incumbent housing developer's optimization problem is characterized as follows:

$$
\Pi_{t}^{d}=\max _{z_{t}} q_{t} A_{t}^{h} z_{t}^{\alpha}-v_{t} z_{t}
$$

where $q_{t}$ represents the selling price of a new housing unit at the end of period $t$, and $v_{t}$ is the land price that a housing developer must pay to the government.

We assume there are many housing developers each period. The equilibrium entry level of housing developers, $M_{t}$, is pinned down by the following free-entry condition:

$$
\Pi_{t}^{d}=\Psi_{t}
$$

\subsection{Competitive Spatial Equilibrium}

Next, we formalize the definition of equilibrium in our two-region benchmark economy with a rural area and a city.

Equilibrium: Given the government policy parameters $\left\{\ell_{t}, \psi\right\}_{t=0}^{\infty}$ and the initial city housing stock $H_{0}$, an equilibrium is a list of prices $\left\{p_{t}, q_{t}, w_{t}^{m}, v_{t}\right\}_{t=0}^{\infty}$; a list of individual $\left\{z_{t}, x_{t}^{f}, x_{t}^{m}, c_{t}^{f}, c_{t}^{m}\right\}_{t=0}^{\infty}$ and aggregate quantities $\left\{N_{t}^{m}, N_{t}^{f}, M_{t}, z_{t}, T_{t}\right\}_{t=0}^{\infty}$; and a migration cutoff value $\left\{\epsilon_{t}^{*}\right\}_{t=0}^{\infty}$ with the following properties: 
1. Given the price sequence, workers maximize their lifetime utility and housing developers maximize their current-period profit.

2. The cutoff of the mobility cost, $\epsilon_{t}^{*}$, is determined by

$$
V_{t}^{M}\left(\epsilon_{t}^{*}\right)-\epsilon_{t}^{*}=V_{t}^{R}\left(\epsilon_{t}^{*}\right)
$$

3. The number of housing developers is determined by the free-entry condition:

$$
\Pi_{t}^{d}=\Psi_{t}
$$

4. The land market clears:

$$
M_{t} z_{t}=\ell_{t}
$$

5. The housing market clears:

$$
M_{t} A_{t}^{h} z_{t}^{\alpha}=\Delta F_{t}^{*}
$$

6. The manufactured goods market clears:

$$
\int_{0}^{\epsilon_{t}^{*}} c_{t}^{m}(\epsilon) d F+x_{t}^{m}\left(1-F\left(\epsilon_{t}^{*}\right)\right)+r^{*}\left[F\left(\epsilon_{0}^{*}\right) b_{0}+\sum_{\tau=1}^{t-1}\left(F\left(\epsilon_{t}^{*}\right)-F\left(\epsilon_{t-1}^{*}\right)\right) b_{\tau}\right]+M_{t} \Psi_{t}=A_{t}^{m} F\left(\epsilon_{t}^{*}\right) .
$$

7. The agricultural goods market clears:

$$
\int_{0}^{\epsilon_{t}^{*}} c_{t}^{f}(\epsilon) d F+x_{t}^{f}\left[1-F\left(\epsilon_{t}^{*}\right)\right]=A_{t}^{f}\left(1-F\left(\epsilon_{t}^{*}\right)\right)
$$

Note that, for the mortgage interest payment, the aggregation is over different cohorts based on their arrival in the city, $\tau .^{8}$ This information is necessary since the mortgage payment can be different across workers in the city.

The equilibrium housing prices are given by

$$
q_{t}=\frac{\psi F\left(\epsilon_{t-1}^{*}\right)}{(1-\alpha) A_{t}^{h}}\left[\frac{F\left(\epsilon_{t}^{*}\right)-F\left(\epsilon_{t-1}^{*}\right)}{A_{t}^{h} \ell_{t}}\right]^{\frac{\alpha}{1-\alpha}} .
$$

Equation (23) indicates that housing prices depend positively on the size of endogenous migration flows $\left(F\left(\epsilon_{t}^{*}\right)-F\left(\epsilon_{t-1}^{*}\right)\right)$ and stocks $\left(F\left(\epsilon_{t-1}^{*}\right)\right)$ but negatively on the availability of land. Migration flows are in turn driven by productivity growth in the city and access to mortgage financing.

\footnotetext{
${ }^{8}$ Such aggregation would have been much more complicated with rental or secondary market purchases.
} 
Notably, $\epsilon_{t}^{*}$ solves the locational no-arbitrage (mobility) condition,

$$
V_{t}^{M}\left(\epsilon_{t}^{*} ;\left\{q_{j}\right\}_{j=t}^{\infty}\right)-\epsilon_{t}^{*}=V_{t}^{R}\left(\epsilon_{t}^{*}\right)
$$

Note that both $V_{t}^{M}\left(\epsilon_{t}^{*} ;\left\{q_{j}\right\}_{j=t}^{\infty}\right)$ and $V_{t}^{R}\left(\epsilon_{t}^{*}\right)$ depend on the sequences of relative productivity of manufacturing to agricultural production $\left(\left\{A_{j}^{m}\right\}_{j=t}^{\infty}\right)$ and relative prices $\left(\left\{q_{j}, p_{j}\right\}_{j=t}^{\infty}\right)$, the current flow of land supply $\left(\ell_{t}\right)$, as well as the down payment requirement at any hypothetical time of purchase $\tau\left(\phi q_{\tau}\right)$. Thus, equilibrium housing prices $\left(\left\{p_{j}\right\}_{j=t}^{\infty}\right)$ must be solved dynamically based on sequences of all the relevant equilibrium conditions. To avoid further complexity, we restrict our attention to the case without reverse migration. In this case, urban opportunities are strong enough to prevent migrants from moving back to rural areas.

\subsection{The Case of Multiple Cities}

The model in the previous section restricts the analysis to a single city. We now extend the model to the case of multiple cities. Suppose there are cities $I>1$. All of the cities are identical and have access to the same technology to produce manufactured goods that can be costlessly traded across cities. The cities differ in two aspects: (i) the relative productivity of the manufacturing sector, $\left\{A_{i, t}^{m}\right\}_{i=1}^{I}$, and (ii) the availability of land (exogenously) supplied by the government, $\left\{\ell_{i}\right\}_{i=1}^{I}$. As a result, equilibrium wages and housing supply and demand are city specific.

In the interest of tractability, city selection is determined by lottery. The probability that a rural worker will be assigned to city $i$ is denoted by $\pi_{i}$, where $\sum_{i=1}^{I} \pi_{i}=1$. The city labor markets are segmented because labor mobility across cities is not permitted. ${ }^{9}$ As a result, in equilibrium, wages across cities do not equalize. As such, once a rural worker is assigned to city $i$, his location choice afterward is to either continue to stay in city $i$ or move back to the rural area.

For a worker of type $\epsilon$, the utility cost of migrating from the rural area to any of the $I$ cities is represented by $\epsilon$. Let $V_{i, t}^{M}(\epsilon)$ denote the value function for a worker of type $\epsilon$ who migrates to city $i$ in period $t$ and solves this optimization problem:

$$
\begin{gathered}
V_{i, t}^{M}(\epsilon)=\max U\left(c_{i, t}^{m}, c_{i, t}^{f}, h_{i, t}\right)+\beta \max \left\{V_{i, t+1}^{C}\left(\epsilon, b_{i, t}\right), V_{t+1}^{R}(\epsilon)\right\}, \\
\text { s.t. } \quad c_{i, t}^{m}+p_{t} c_{i, t}^{f}+q_{i, t} h_{i, t}=w_{i, t}^{m}+b_{i, t}, \\
b_{i, t} \leq(1-\phi) q_{i, t} h_{i, t} .
\end{gathered}
$$

\footnotetext{
${ }^{9}$ Based on city total migration flows over the sample period 1998-2008, we calculated net migration flows from Beijing to other cities (including Shanghai) and from Shanghai to other cities (including Beijing) and found them within \pm 4 percent. Thus, ignoring the city-to-city migration does not seem to be at odds with the evidence.
} 
This problem is similar to the one for the single-city model, but in this case wages and housing prices are determined at the city level. The ex-ante value associated with migration is represented by $V_{t}^{M}(\epsilon)$, which equals the expected payoff from living in any one of the $I$ cities, $V_{t}^{M}(\epsilon)=\sum_{i} \pi_{i} V_{i, t}^{M}(\epsilon)$. Therefore, a worker of type $\epsilon$ will migrate to an urban area in period $t$ when following condition is satisfied, $V_{t}^{M}(\epsilon)-\epsilon \geq V_{t}^{R}(\epsilon)$. In each period $t>0$, there exists a cutoff $\epsilon_{t}^{*}$, below which workers move to an urban area. The threshold $\epsilon_{t}^{*}$ can be pinned down from the following indifference condition:

$$
V_{t}^{M}\left(\epsilon_{t}^{*}\right)-\epsilon_{t}^{*}=V_{t}^{R}\left(\epsilon_{t}^{*}\right)
$$

Housing developers in each city are endowed with the same technology to convert land into houses. The entry fee collected by the government in each city will obey these rules, so the entry fee collected by city $i$ in period $t$ positively depends on the existing housing stock in city $i: \Psi_{i, t}=\psi H_{i, t-1}$, where $\psi>0$. Therefore, the number of housing developers in each city, $M_{i, t}$, will be determined by the following free-entry condition, $\Pi_{i, t}^{d}=\Psi_{i, t}$.

The housing and land markets will clear in each city subject to the exogenous land supply controlled by the government in each city. The market-clearing conditions in city $i$ can be derived as follows:

$$
\begin{aligned}
M_{i, t} z_{i, t} & =\ell_{i, t}, \\
M_{i, t} A_{i, t}^{h} z_{i, t}^{\alpha} & =\Delta F_{i, t}^{*} .
\end{aligned}
$$

Similar to the previous analysis, housing prices prices can be explicitly solved as follows:

$$
q_{i, t}=\frac{\psi F\left(\epsilon_{t-1}^{*}\right) \pi_{i}}{(1-\alpha) A_{i, t}^{h}}\left[\frac{\left[F\left(\epsilon_{t}^{*}\right)-F\left(\epsilon_{t-1}^{*}\right)\right] \pi_{i}}{A_{i, t}^{h} \ell_{i, t}}\right]^{\frac{\alpha}{1-\alpha}}
$$

Since manufactured goods are mobile, their markets should clear at the national level.

\section{Quantitative Analysis}

The objective of the quantitative analysis is to evaluate the role of structural transformation in China's housing boom. To that end, we first apply the U.S. experience to project the path along which China might complete its structural change; we then calibrate the model so that the simulated economy can mimic some stylized facts about the early stages of development in China. We compare the model's prediction with the data to assess how much housing price growth can be rationalized by the model (data sources and definitions are provided in Appendix C). We also perform some counterfactual exercises to explore the 
roles of financial frictions and land policy in housing price growth. Finally, we extend the quantitative analysis to the multiple city case, which allows us to evaluate for various cities the different contributions structural change might make to housing price growth.

\subsection{Projection of the Chinese Population and Land Distribution}

In 1840 almost 90 percent of the total U.S. population lived in rural areas. This percentage steadily declined to about 3 percent in 1990 and has since remained at about 3 percent. Because the fraction of the population living in rural areas is a main indicator of the progress of structural transformation, the United States is viewed as having completed its structural transformation by 1990. In 2012, the agricultural share of employment in China is still over 30 percent and the fraction of urban employment is around 50 percent as can be seen in Figure $3 .^{10}$

Calculating the path of future prices requires making different assumptions about the length of the structural transformation process. In the baseline case, we assume that the path of China's structural transformation will take another 50 years. Under this assumption, in the year 2065 urban employment in China will become steady thereafter. Our algorithm is simply as follows: We assume net migration flow into urban area will continue to grow until the year 2020, and then, it will steadily decline as shown in the top left panel of Figure 4. The definition of net migration flows from rural to urban areas include permanent and temporary permits where many of the latter, mostly renting, but are later granted permanent permits. Overall, the time path for the fraction of urban employment is plotted in the top right panel of Figure 4. By 2065, the fraction of urban employment will reach 95 percent. ${ }^{11}$

We also perform a similar projection algorithm for the residential land supply. We back out the annual residential land supply from the data by using "land space purchased this year by real-estate enterprises" divided by "total land area for inhabitation, mining, and manufacturing", where we assume that the fraction of land for residential use is constant over time. Based on currently available data for China, we extrapolate the residential land supply series to 2065. The stock and the flow are summarized in the bottom panels of Figure $4 .^{12}$

\footnotetext{
${ }^{10}$ While there is discrepancy in the definition of urban areas between these two large economies, the contrast is sharp regardless.

${ }^{11}$ Note that there may be more optimistic projections on the progress of structural transformation in China, with a much faster transition for China than the United States. The conjecture above is provided as a starting point. As a robustness check, we performed various exercises with more optimistic and pessimistic projected paths. While the results have some effects in the very long-run, but they have only a minor impact on the simulated dynamics of housing prices between 1998 and 2012.

${ }^{12}$ The results for the period 1998-2012 do not appear to be extremely sensitive to slightly different paths of the residential land supply.
} 


\subsection{Calibration of the Chinese Economy}

Because of the role of structural transformation in the model, capturing the change in expenditure patterns from agricultural to manufactured goods is key. A simple way to rationalize this is to assume that the utility function takes the constant elasticity of substitution (CES) form $u\left(c_{t}^{m}, c_{t}^{f}\right)=\left[\theta\left(c_{t}^{m}\right)^{\rho}+(1-\theta)\left(c_{t}^{f}\right)^{\rho}\right]^{\frac{1}{\rho}}$, where the elasticity of substitution between the two goods is $1 /(1-\rho)$. An alternative specification with non-homothetic preferences is discussed in Section 4.5. A worker's disutility level from migration is assumed to follow a Pareto distribution with the support on the interval $[1, \infty)$ :

$$
F(\epsilon)=1-\left(\frac{1}{\epsilon}\right)^{\lambda}
$$

Each period in the model corresponds to one year; the subjective discount rate, $\beta$, is set at 0.95 ; and the annual interest rate, $r^{*}$, is set at 5 percent. The down payment ratio $\phi$, the fraction of the house value that the worker must pay in advance is set at 0.3 , which is in line with the data. Productivity in the agricultural sector $A_{t}^{f}$ is normalized to 1 . We further assume that housing productivity $A_{t}^{h}$ is constant over time. Since $A^{h}$ matters only for the unit of housing prices, having housing prices expressed as an index allows the value of $A^{h}$ to be immediately pinned down. The remaining parameters $\left\{\theta, \rho, \alpha, \psi, \lambda, A_{t}^{m}\right\}$ are calibrated to match stylized facts from China's early development stage. The elasticity of substitution parameter, $\rho$, is calibrated to match the growth rate of the expenditure share of agricultural goods from 1998-2012, and the parameter, $\theta$, is chosen to match the average consumption share of nonagricultural goods. The parameter $\alpha$ measures the returns to scale for housing developers and is calibrated to match the housing-land price ratio over 1998-2012. The tail of the Pareto distribution, $\lambda$, is calibrated for the migration utility cost to be 50 percent in consumption equivalence for the mean worker. ${ }^{13} \psi$ is chosen to match the average ratio of licensing fees to housing developers sales revenue over 1998-2012. We finally calibrate $\left\{A_{t}^{m}\right\}$ to exactly match the projected population distribution between rural and urban areas from 1998-2065. ${ }^{14}$ The observed path of net migration are highlighted in blue in the top left panel of Figure 5. The parameters in the calibration are reported in Table 1.

\footnotetext{
${ }^{13}$ Zhu and Zhang (1996) estimate migration costs to be about 17.4 percent of migrant's income where the migrant's income could be viewed as an average of his/her rural and city income. Given the city-rural-income gap and the consumption propensity, we obtain the 50 percent figure. The high migration cost is a result of the restricted "hukou" system that limits regional mobility.

${ }^{14}$ In the absence of quality time-series data for urban-rural wage ratios, we have targeted migration flows from rural areas into cities.
} 


\subsection{Quantitative Results: National Benchmark}

The main quantitative analysis focuses on the model's ability to generate movements in housing. The model generates yearly predictions for the variables that can then be compared with the data. The evaluation of the model's performance is based on average growth rates for the period 1998-2012. The results are summarized in Table 2 (top panel).

In China, the average housing price growth rate is 9.7 percent and the model predicts 6.4 percent in the overall sample. Nevertheless, the performance improves by measuring the model's generated data in a restricted subsample for the period 2003-2007. The model is able to generate a housing price growth rate of 6.6 percent while the data counterpart is 9.1 percent. This finding suggests that in the aftermath of the financial crisis, the contribution of migration to house prices has weakened relative to other factors.

Another way to measure the fit of the model is to adopt the development accounting approach used by Caselli (2005). We compute the model's success rate, which is defined as follows:

$$
\text { success rate }=\operatorname{var}(\log (\operatorname{model})) / \operatorname{var}(\log (\text { data })) \text {. }
$$

As a complementary measure, we propose to use the normalized mean square error (NMSE) to evaluate the model's performance:

$$
\mathrm{NMSE}=\frac{\sum_{t}\left(x_{t}^{M}-x_{t}^{D}\right)^{2}}{\sum_{t}\left(x_{t}^{D}\right)^{2}}
$$

where $x_{t}^{m}$ and $x_{t}^{D}$ denote the time-series of the model and the data counterpart, respectively. The findings are reported in Table 2. The implied measures are consistent with the previous observation, but the overall fit of housing prices is significant.

Figure 5 shows the model's performance along the entire dynamic path, with log-prices and the initial values of each series normalized to zero. In terms of levels, the model predicts a change in the housing price ratio of 2.36 for the period 1998-2012, whereas in the data the change is 2.93 .

A closer look at Figure 5 suggests that housing prices in the data behave differently over the three subperiods. In the period 1998-2002, the model overpredicts the housing price growth trend. This period was characterized by a significant slowdown in housing prices, with an average annual growth rate of 3.2 percent. This finding is consistent with the Asian financial crisis in 1997, the layoff of state owned enterprises (SOE) employees over 19992002, and the burst of the dot-com bubble in 2001. Because we do not explicitly model the SOE layoffs, the model captures only 65.6 percent of housing price movements. In the second period, 2003-2007, housing prices skyrocket, with an average annual growth rate of 
15.1 percent. This finding is consistent with fast economic growth and further deregulation of the migration policy and the financial sector in conjunction with the government's reduced control of urban land and housing permits. For this subperiod, the model captures housing price movements from 2004 forward and explains only 65.1 percent of this movement because of underprediction carried from the previous subperiod.

Remark: It is informative to consider the case of a pure rental market, re-calibrating the model by setting $\phi=r^{*} /\left(1+r^{*}\right)=4.76 \%$. In this case, the new migrants are indifferent between owning or renting. With no down payment requirement, it is easier for rural workers to migrate to the city. Our quantitative results suggest that the effects from this increased migration flow dominate the general equilibrium effects, which results in the model predicting higher housing prices. In this case, the model accounts for 87.0 percent of the movement in housing prices. With tenant choices, the model's predictive power would be somewhere between the benchmark case and the pure rental case. Thus, one may conclude that our benchmark model provides a conservative prediction of the changes in housing.

The model can be used to understand the relative importance of the different driving forces of housing prices over the sample period 1998-2012. To do this, we decompose the contributions of the various factors (the down payment constraint, entry fee, land supply policy, and productivity of the manufacturing sector) relative to the benchmark model. This decomposition maintains the calibrated parameters of the benchmark values and changes one factor at a time. More specifically, the decomposition considers the following counterfactuals for each factor:

- Entry fee: The magnitude of the entry fee paid by land developers depends positively on the current city population. A higher value of $\psi$ implies a higher entry fee and fewer developers. The benchmark value in the calibration is 4.5. In the counterfactual analysis, the value of $\psi_{t}$ varies each period so that government revenue remains constant at its level in the initial period $t=0$. When the population of the city grows, the computed value of $\psi_{t}$ decreases over time, inducing the entry of housing developers and increasing housing production. In equilibrium, more houses lead to lower housing prices and a higher level of migrants. By comparing the counterfactual price with the benchmark price, it is possible to compute the relative contribution of the entry fee.

- Land supply: In the counterfactual experiment, the flow of land supplied by the government to the market is fixed at the initial high level, $\ell_{t}=\ell_{0}$, for all $t$. The relative increase in the land supply generates an upward shift in the housing supply, leading to a decrease in housing prices and an increase in the number of migrants. 
- Mortgage financing (down payment constraint): The counterfactual considers no mortgage financing, $\phi=1$, instead of the benchmark value of 0.3 . The elimination of mortgage financing should drive down housing demand and, hence, housing prices.

- Productivity: Productivity acts as the residual in the decomposition exercise. That is, within our framework, in the absence of other variations beyond the above-mentioned factors, productivity growth explains the remaining portions of the increases in housing prices and the average fraction of migrants in the city population.

The results of the decomposition are summarized in Table 2 (bottom panel), which shows by time period the percentage increases in housing prices due to each single factor. For example, in the case of land supply controls, the decomposition compares the benchmark with an economy that has the same increased availability of land as in the initial years (1998-2002). The increased availability of land leads to a decrease in housing prices and an increase in the migrant population in the city. The data for the period 1998-2012 reveal the following: Tightening the land supply policy in the benchmark case contributes to 36.0 percent of housing price growth. The decomposition results suggest that supply factors are the most important factor for increases in housing prices, accounting for 62.7 percent of the total change in the model, whereas productivity (income) accounts for only about 20 percent. The role of productivity becomes more important over time while the contribution of supply factors diminishes. This would be consistent with the rising role of an effective "world factory" that China played during its urbanization process. Over the entire sample period, the contributions of access to credit to all indicators are below 20 percent.

\subsection{Quantitative Results: Multiple-City Model}

One may question whether structural transformation can still explain the rapid growth of housing prices in large cities. This section explores the contribution of urbanization to the dynamics of housing prices at the city level. Although the size of migration flows could be responsible for the rapid increase in housing prices in many cities in China, other factors (i.e., different housing supply restrictions and land regulations) could also be important. For better illustration, the analysis is restricted to the two largest cities in China: Beijing and Shanghai. These two cities accounted for 6.5 percent of the entire urban population in 2011.

As shown in Figure 6, the rapid population growth naturally led to housing booms in these two major cities with housing prices growing above the national average. Housing prices in Beijing remained relatively stable until 2005; in contrast, housing prices in Shanghai grew continuously, with a more rapid trend starting in 2004. 
The multiple-city model has to be consistent not only with the rural-urban migration but also with the change in city population. The quantitative analysis maintains the values of the preference and technology parameters of the single-city model with these exceptions: the exogenous probability of migrating to city $i$ from the rural area, $\pi_{i}$; the relative manufacturing productivity in city $i,\left\{A_{i, t}\right\}$; and the total residential land area in city $i,\left\{L_{i, t}\right\}$. When there are $I>1$ cities in the urban area, the share of the population in city $i, n_{i, t}$, is denoted as follows, where $N_{i, t}$ denotes the total population in city $i$ and $N_{t}^{R}$ denotes the total population in the rural area:

$$
n_{i, t}=\frac{N_{i, t}}{\sum_{i=1}^{I} N_{i, t}+N_{t}^{R}} .
$$

When the total population is normalized to 1 , the growth rate of $n_{i, t}$ can be shown to be equivalent to the growth rate of $N_{i, t}$ :

$$
\frac{\triangle N_{i, t}}{N_{i, t}}=\frac{\triangle n_{i, t}}{n_{i, t}} .
$$

Since each period a fraction $\pi_{i}$ of migrants moves to city $i$, it is implied that $\triangle N_{i, t}=-\pi_{i} N_{t}^{R}$. Therefore, the growth rate of $n_{i, t}$ can be represented as follows:

$$
\frac{\triangle n_{i, t}}{n_{i, t}}=\frac{\triangle N_{i, t}}{N_{i, t}}=-\pi_{i} \frac{\triangle N_{t}^{R}}{N_{t}^{R}} \frac{N_{t}^{R}}{N_{i, t}} .
$$

The rule for assigning migrants to a particular city $\pi_{i}$ can be estimated from the equation above. The change in the fraction of migrants in the populations of Beijing and Shanghai between 1994 and 2011 was 52.75 percent and 45.65 percent, respectively. ${ }^{15}$ Therefore, using equation (25), for that period the fractions of migrants flowing to Beijing and Shanghai are 3.4 and 3.9 percent, respectively.

In 1994, 1.03 percent and 1.17 percent of the total population of China lived in Beijing and Shanghai, respectively; 26.8 percent lived in other cities, and 71.0 percent lived in rural areas. Given the values of $\left\{n_{B, 0}, n_{S, 0}, \pi_{B}, \pi_{s}\right\}$, it is straightforward to calculate the sequences of $\left\{n_{B, t}\right\}$ and $\left\{n_{S, t}\right\}$ from $n_{i, t+1}=n_{i, t}+\pi_{i}\left(n_{t}^{R}-n_{t+1}^{R}\right), i \in\{B, S, O\}$.

To complete the calibration of the multiple-city model it is necessary to determine the land supply and the entry fee in each city. The total land area is 164, 100 square kilometers in Beijing and 82, 400 in Shanghai. The annual residential land supply in each city from data is still defined by using "land space purchased this year by real-estate enterprises" divided by "total land area for inhabitation, mining and manufacturing," where we have assumed that the fraction of land for residential use is constant over time in each city. The data for the

\footnotetext{
${ }^{15}$ We use a longer span of data to capture the long-run trend and mitigate large fluctuations in migration flows from events such as the SOE layoffs and the SARS epidemic (discussed below).
} 
residential land supply in each city are plotted in Figure 6. Consistent with the aggregate model, in each city an entry fee is collected by the local government.

The migration flow is combined with supply factors to generate a sequence of housing prices for each city for the period 1998-2012. As shown in Table 3 (top panel), the average housing price growth rate in the data is 4.5 and 12.4 percent in Beijing and Shanghai from 1998 to 2012, respectively, while our model predicts 8.1 percent for each city. If we restrict the analysis to the period 1998-2007, our model performs better only in predicting housing price growth in Shanghai. As for the success rate, the model seems to be successful in predicting housing price growth in both cities. The NMSE remains low for housing prices in both cities. The dynamic evolution of model-predicted housing prices over 1998-2012 with the data is summarized in Figure 7. The model captures not only an important fraction of the level change, but also the dynamic adjustment of house prices. To understand the differential patterns across these two cities it is useful to decompose the sample into three subperiods:

- 1998-2002: During this period the economy was affected by the financial crises in Asia and the burst of the dot-com bubble. During these years, China had high levels of unemployment, especially for SOE workers. The gradual but deepening economic reform encouraged more and more private enterprises to enter the market. Beijing, the capital of China, was the headquarters for many SOE; thus, more workers were laid off in Beijing than in Shanghai.

- 2003-2007: The spread of the SARS virus affected Beijing more severely in 2002 than it did Shanghai in 2003 and reduced migration to Beijing. After 2003, the period was characterized by rapid growth leading up to the 2008 Summer Olympic Games in Beijing.

- 2008-2012: This is the burst of global financial crisis period.

The model captures a "flying geese" pattern of city development. As an early starter, Beijing has transferred more and more industrial production to Shanghai and, hence, the latter has attracted a larger labor force. This fact explains why housing prices in Shanghai grew faster than in Beijing. Across the two cities and the three subperiods, the model performs quite well except for Beijing in the second subperiod. As mentioned, the spread of the SARS virus significantly reduced migration to Beijing. Since housing prices in the model are critically driven by migration, the model predicts a much larger decline in housing prices than found in the data. This underprediction is also responsible for the relatively low average growth rate of housing prices.

Historically, Beijing and Shanghai have been the main industrialized cities in China. Ever since the implementation of reform and open policy in China, these cities have received the 
most rural migrants. The fact that the model can explain a sizable fraction of housing price growth in both cities affirms the idea that structural change plays a crucial role in housing price growth in industrialized cities.

In the model, both cities have similar migration flows. The main differences in price dynamics have to be the result of institutional differences operating through the supply factors. To assess the relative importance of all factors, but in particular on the supply side, we decompose the relative contribution of each factor for the full sample by subperiods, as shown in Table 3 (bottom panel).

For both cities, supply factors are the most important driver of the increase in housing prices, accounting for an average of 60.2 percent in Beijing and 53.2 percent in Shanghai. These numbers are slightly lower than that for the nation reported in the single-city model. The contribution of productivity in Beijing is similar to that at the national level, whereas productivity plays a noticeably more important role in Shanghai, indicating that the agglomerations could be critical in the largest city of China. We also find that productivity becomes more important over time for explaining housing price movements during the last subperiod. In the initial subperiod, the relatively higher income growth in Shanghai drives the variation in housing prices across the two cities. The relatively low productivity in Beijing captures the low growth in employment and migration due to the layoff of SOE workers. Even though the relative contribution of productivity in the two cities is comparable in the first and second subperiod, it is important to note the stagnation of housing prices in Beijing due to a productivity slowdown. Again, the impact of the SARS virus is captured by low migration flows and, hence, low income growth (productivity). Land supply becomes more important in explaining Beijing's housing prices during 2008-2012. The regulation of housing developments through fees and land supply also plays an important role.

The quantitative findings indicate that the process of structural transformation can be an important driver of housing prices, not only at the national level but also for large cities such as Beijing and Shanghai, where housing booms have been particularly noticeable.

\section{Extensions}

This section extends the baseline model along several dimensions. The objective is to assess the robustness of the main findings obtained in the benchmark model. The first modification smooths the volatile migration flows. The next extension departs from direct ownership of housing and considers the case where migrants rent houses perpetually. We then introduce housing quality into our model in a parsimonious manner, to examine the potential role of home upgrading in China's housing boom. Moreover, we consider savings, the consumption 
valuation of housing and the investment value of housing, to check the extent to which the predictability of house price in China could be enhanced. Finally, we show that our model with standard non-homothetic preferences is isomorphic to one with CES preferences.

\subsection{Migration Flow Smoothing}

In the baseline model, the annual flow of migrant workers is targeted for calibrating the relative productivity growth between the manufacturing and agricultural sectors. The volatility of migration flows could imply unnecessary choppiness in productivity measures. It is therefore natural to consider a 5-year moving average of the series. In doing so, we can also indirectly capture possible effects from delayed housing purchases present in the data. As can be seen in Figure 8 (top left), the results are essentially unchanged relative to the baseline model.

\subsection{Pure Housing Rental}

The baseline model assumes 100 percent homeownership in the urban areas. While the homeownership rate is very high in China (over 80 percent), it is clear that some migrant workers might not be able to afford to purchase a house immediately after their arrival in the city. To assess the importance of this assumption, this section explores another extreme: assuming that all migrants rent houses perpetually.

The case of tenant-occupied residency is captured by setting $\phi=r^{*} /\left(1+r^{*}\right)$, where an agent migrating in period $\tau$ signs a long-term rental agreement paying each period a fixed rent $d_{\tau}$ based on the housing price when the tenant moved in. Figure 8 (top right) shows some noticeable improvements over the benchmark case. The prediction of housing price growth under the pure rental case improves from 66 percent to 78 percent. This is because renting mitigates the financial barriers to migration, thus leading to the prediction of higher growth rates of housing. The differences between these two extreme cases can be indirectly interpreted as the contribution of homeownership to housing prices.

\subsection{Housing Quality}

The benchmark model assumes that housing is a necessity to live in the urban area without adding valuation to households. This section considers a simple departure that allows for variations of housing quality entering a city worker's utility function in a parsimonious manner:

$$
U\left(c_{t}^{m}, c_{t}^{f}, h_{t}\right)= \begin{cases}u\left(c_{t}^{m}, c_{t}^{f}\right)+\kappa q_{t}^{\varsigma} & \text { if } h_{t} \geq 1 \\ -\infty & \text { otherwise }\end{cases}
$$


where $\kappa$ and $\varsigma$ are positive parameters. That is, while the equilibrium quantity of housing consumption is at one unit, its quality reflected by price is valued. This additional valuation captures not only the standard housing quality component but also the signaling value of housing as proposed by Wei, Zhang, and Liu (2012).

The addition of housing quality does not affect the individual optimization at the intensive margin, but in equilibrium, factors influencing housing prices will affect a city worker's utility, and, hence a rural worker's migration decision. The additional two parameters are calibrated to match the relative urban-rural wage ratio and the urban wage growth rate. The results depicted in Figure 8 (bottom left) suggest comparable magnitudes of improvement to the case of tenant-occupied housing.

\subsection{Savings and Multiple Housing Holdings}

The last extension allows individuals to save and own multiple housing units. While individuals have consumption valuation of housing, they can also invest in housing to take advantage of its rising prices. The model is highly stylized but allows capturing these two additional margins with minimal departures from the baseline model.

In the extended formulation, rural workers can save using a riskfree asset $A_{t}$ with a rate of return $r_{a}$. To simplify the analysis, we consider the case of a linear utility in the consumption aggregator, $C$, and assume that the rate of return satisfies $\left(1+r_{a}\right) \beta=1$. Consequently, rural workers will not save unless they plan to move to the city to cover the down payment.

The city workers utility function is modified to allow additional units of housing acquired for investment purposes and for additional utility:

$$
U\left(C_{t}, h_{\tau}\right)=\left\{\begin{array}{ll}
C_{t}+\gamma \ln \left(h_{t}\right) & h_{t} \geq \underline{h} \\
-\infty & h_{t}<\underline{h}
\end{array},\right.
$$

where $\underline{h}=1$ represents the housing necessity component and $h_{t}-\underline{h}$ measures the additional housing holdings. In an environment with rapidly growing housing prices it is natural to assume housing rate of return dominance, requiring

$$
\frac{q_{t+1}}{q_{t}}+\frac{\gamma}{q_{t} h_{t}} \geq 1+r_{a}
$$

Under this condition, the optimized value function for a city stayer, aside from a constant term depending on wage, becomes

$$
v^{c s}\left(h_{t} ; q_{t}\right)=\left(1+r_{a}\right) q_{t} h_{t}+\gamma \ln \left(h_{t}\right)-\frac{\gamma \beta}{1-\beta} \ln \left(q_{t}\right) .
$$

Housing valuation depends positively on the quantity, $h_{t}$, and the value of housing, $q_{t} h_{t}$, but 
negatively on the price, $q_{t}{ }^{16}$

The migrant problem solves

$$
\begin{gathered}
v^{m}\left(a_{\tau}\right)=\max \left\{C_{\tau}+\gamma \ln \left(h_{\tau}\right)+\beta v^{c s}\left(h_{\tau+1} ; q_{\tau+1}\right)\right\} \\
\text { s.t. } \quad C_{\tau}+\phi q_{\tau}+a_{\tau+1}+q_{\tau+1} h_{\tau+1}=w_{\tau}+\left(1+r_{a}\right) a_{\tau}, \\
b_{\tau} \leq(1-\phi) q_{\tau}, \\
C_{\tau}, a_{\tau+1}, h_{\tau+1} \geq 0 .
\end{gathered}
$$

The optimal housing investment decision rule is determined by

$$
h_{\tau+1}=\frac{\gamma \beta}{\left(q_{\tau}-\beta q_{\tau+1}\right)} .
$$

Those who plan to move to the urban area need to cover the down payment of the housing necessity, $\underline{h}=1$. Given the quasi-linear specification of the utility function, individuals in the rural area who are willing to move will save their full income until they have sufficient funds to cover the down payment. In the absence of consumption, the saving level $T$ periods before a potential moving date is defined as

$$
A_{\tau}^{T}=\sum_{t=1}^{T} A_{\tau-t}\left(1+r_{a}\right)^{\tau-1}
$$

The optimal time duration of savings is determined by solving $T^{*}$ that satisfies

$$
\begin{aligned}
T^{*} & =\arg \min _{T} A_{\tau}^{T}-a_{\tau} \geq 0 . \\
a_{\tau} & \geq \max \left\{\frac{\phi q_{\tau}-w_{\tau}}{1+r_{a}}, 0\right\}
\end{aligned}
$$

When the potential migrant is willing to move to the city ( $\varepsilon$ is sufficiently low), he or she is able to move after the date $\tau \geq T^{*}$.

The model with savings requires calibrating the parameter $\gamma$ that targets the observed housing expenditure share. In contrast with to the previous simulations, the addition of savings behavior allows for smoother movements of housing prices. This is because migrants can anticipate the movement to the city and bring more funds than the initial wage income in period $\tau$. As a result, there is an initial jump in housing prices due to the endogenous decision of the moving date.

The quantitative findings associated with this extension are depicted in Figure 8 (bottom right). This version of the model shows comparable magnitudes of improvement in housing prices to the extension of tenant-occupied housing, suggesting that this extension is unlikely

\footnotetext{
${ }^{16}$ Details about the derivation can be found in supplemental Appendix.
} 
to be critical for explaining the housing boom in China.

\subsection{Non-Homothetic Preferences}

In the standard structural transformation literature, it is common to consider non-homothetic preferences to account for the transition from agriculture to manufacturing/services. For a detailed review of the literature, see Herrendorf, Rogerson, and Valentinyi (2014). In this subsection we show that our baseline specification with CES preferences is isomorphic to the standard non-homothetic preferences as proposed by Kongsamut, Rebelo, and Xie (2001).

Recall individual preferences defined by a CES utility index $U\left(x_{t}^{f}, x_{t}^{m}\right)=\left[\theta\left(x_{t}^{f}\right)^{\rho}+(1-\right.$ $\left.\theta)\left(x_{t}^{m}\right)^{\rho}\right]^{\frac{1}{\rho}}$ and solving the optimized agricultural expenditure share, $\sigma_{t}^{f}\left(p_{t}\right)$, gives

$$
\sigma_{t}^{f}\left(p_{t}\right)=\frac{x_{t}^{f}}{x_{t}}=\left(1+\left[\frac{(1-\theta)}{\theta} \frac{1}{p_{t}^{\rho}}\right]^{\frac{1}{1-\rho}}\right)^{-1}
$$

Next, consider standard non-homothetic preferences in the Stone-Geary form, $U\left(x_{t}^{f}, x_{t}^{m}\right)=$ $\left(x_{t}^{f}-\underline{x}^{f}\right)^{\eta}\left(x_{t}^{m}\right)^{1-\eta}$, with a minimum consumption requirement of agricultural goods, $\underline{x}^{f}$. This preferences give an optimized agricultural expenditure share, $\sigma_{t}^{f}\left(x_{t}\right)$ :

$$
\sigma_{t}^{f}\left(x_{t}\right)=\eta+(1-\eta) \frac{x^{f}}{x_{t}} .
$$

By the appropriate choice of $\bar{x}^{f}$, we show that the trend of the two expenditure shares is the same. Given the baseline values of our preference specification $\theta=0.50$ and $\rho=0.80$, we calibrate the non-homothetic model to obtain $\eta=0.10$ and $\bar{x}^{f}=0.50$. Under the predicted path of relative prices in the baseline model $\left\{p_{t}\right\}$, the resulting expenditure shares in the two setups are depicted in Figure 9 for the period 1998-2013. Consequently, the predictions on housing price growth rates under the preference specifications are quantitatively equivalent.

\section{Conclusions}

This paper uses a dynamic general equilibrium framework to investigate the role of structural transformation in the rapid growth of housing prices in China. The benchmark economy incorporates three major channels: (i) structural transformation, the increased productivity of the manufacturing sector that leads to higher income and greater ability to pay; (ii) the relatively inelastic supply of housing due to incremental city land released by the government and the controlled entry of real estate developers through entry fees; and (iii) urbanization, ongoing rural-urban migration that increases demand for urban housing. The quantitative findings suggest that the process of structural transformation and the resulting urbanization 
are important drivers of housing price movements in China. The model accounts for 80.5 percent of housing prices over 1998-2012 at the national level. The model performance improves during the pre-financial tsunami period, accounting for 86.1 percent of housing over 1998-2012. Even for the two largest cities, Beijing and Shanghai, the model accounts for 82.8 percent and 60.2 percent of housing price growth, respectively.

What important implications for policy are derived from this research? One is that China's housing prices are apparently driven primarily by structural transformation and the induced migration from rural to urban areas. Thus, if China's urban housing boom is a concern, then our results suggest that to cool down the housing market, proper control of supply factors such as land controls and developer entry regulations are likely to be much more effective than mortgage restrictions.

In line with our model prediction, the tightened housing policy together with the growth slowdown has led to a sluggish housing market in recent years. Events such as the turmoil in the stock market combined with lower expectations about future growth are likely to slow migrations flows from rural to urban areas. In the absence of supply changes, reduced migration flows could have negative impacts on the housing market. Our approach is flexible enough to be applied to different economic environments, and the implications of our analysis have a larger scope than the Chinese experience. For example, in the case of U.S. urbanization the pace of migration was relatively slow, which, combined with greater availability of land, led to modest growth of housing prices during the whole process. On the contrary, countries such as Japan, Korea, and Taiwan have experienced much faster migration flows and with limited land availability, the urbanization process generated a noticeable housing boom.

\section{References}

[1] E. W. Bond, R. Riezman, and P. Wang (2014): "Trade, Urbanization and Capital Accumulation in a Labor Surplus Economy," Working Paper, Washington University in St. Louis.

[2] K. Chen and Y. Wen (2014): "The Great Housing Bubble of China," Mimeo.

[3] M. Davis and J. Heathcote (2005): "Housing and the Business Cycle," International Economic Review, 46, 751-784.

[4] Y. Deng, J. Gyourko, and J. Wu (2015): "Evaluating the Risk of Chinese Housing Markets: What We Know and What We Need to Know," NBER, Cambridge, MA.

[5] H. Fang, Q. Gu, and L. Zhou (2014): "The Gradients of Power: Evidence from the Chinese Housing Market," National Bureau of Economic Research. 
[6] C. Garriga, R. Manuelli, and A. Peralta-Alva. (2012): "A Model of Price Swings in the Housing Market," Working Paper 2012-022, Federal Reserve Bank of St. Louis.

[7] G. Glomm, (1992): "A Model of Growth and Migration," Canadian Journal of Economics, 25, 901-922.

[8] G.D. Hansen and E.C. Prescott. (2002): "Malthus to Solow," American Economic Review, $92(4)$, 1205-1217.

[9] B. Herrendorf, R. Rogerson, and A. Valentinyi (2014): "Growth and Structural Transformation," Handbook of Economic Growth, (2), 855-941.

[10] P. Kongsamut, S. Rebelo, and D. Xie. (2001): "Beyond Balanced Growth," Review of Economic Studies, 68 (4): 869-882.

[11] P.J. Liao, Y.-C. Wang, P. Wang, and C.K. Yip (2014): "Education and Rural-urban Migration: The Role of Zhaosheng in China," Working Paper, Chinese University of Hong Kong.

[12] R. E. Lucas, Jr. (2004): "Life Earnings and Rural-Urban Migration," Journal of Political Economy, 112, S29-S59.

[13] R. Ngai and C. Pissarides. (2007): "Structural Change in a Multi-Sector Model of Growth," American Economic Review, 97, 429-443.

[14] T. Tombe and X. Zhu (2015), "Trade, Migration and Productivity: A Quantitative Analysis of China," miemo.

[15] S. Wei, X. Zhang, and Y. Liu. (2012): "Status Competition and Housing Prices," Mimeo.

[16] X. Zhu. (2012): “Understanding China's Growth: Past, Present, and Future," Journal of Economic Perspectives 26 (4), 103-124.

[17] C. Zhu and Y. Zhang. (1996): "Cost and Benefit of Rural Children in the Xianyang Province of China," Population and Economics, 5, 13-22. 
Table 1: Benchmark Parameter Values

\begin{tabular}{lcc}
\hline \multicolumn{1}{c}{ Variable } & Targets & Value \\
\hline Share of nonagricultural goods, $\theta$ & average consumption share of nonagricultural goods & 0.49 \\
Elasticity of substitution, $\rho$ & growth rate of nonagricultural goods expenditure share. & 0.81 \\
Tail index of Pareto distribution, $\lambda$ & average migration utility cost in consumption equivalence & 2.8 \\
Technology developers, $\alpha$ & housing-land price ratio & 0.2 \\
Entry fee, $\psi$ & licensing fee to housing developer's sales revenue & 4.5 \\
Subjective discount rate, $\beta$ & literature & 0.95 \\
Productivity in agricultural sector, $A_{t}^{f}$ & normalization & 1 \\
Down payment ratio, $\phi$ & data & 0.3 \\
Annual interest rate, $r^{*}$ & data & 0.05 \\
\hline
\end{tabular}


Table 2: Model Prediction: National Housing Prices

\begin{tabular}{|c|c|c|}
\hline & \multicolumn{2}{|c|}{ Housing Prices (\%) } \\
\hline & Data & Model \\
\hline "Avg. growth: 1998-2012 & 9.7 & 6.4 \\
\hline Avg. growth: 1998-2007 & 9.1 & 6.6 \\
\hline Ratio of 2012/1998 & 2.93 & 2.36 \\
\hline \multirow[t]{2}{*}{ Ratio of $2007 / 1998$} & 2.08 & 1.79 \\
\hline & Success & NMSE \\
\hline 1998-2012 & 0.60 & 0.0190 \\
\hline 1998-2002 & 2.35 & 0.0016 \\
\hline $2003-2007$ & 0.36 & 0.0082 \\
\hline 2008-2012 & 0.31 & 0.0263 \\
\hline
\end{tabular}

Decomposition of Housing Prices (Percent)

\begin{tabular}{ccccc} 
Period & Entry Fee & Land Supply & Down Payment & Productivity \\
\hline \hline $1998-2012$ & 26.7 & 36.0 & 15.6 & 21.7 \\
$1998-2002$ & 34.5 & 34.6 & 18.9 & 12.0 \\
$2003-2007$ & 28.4 & 32.0 & 14.6 & 25.0 \\
$2008-2012$ & 10.9 & 38.6 & 8.0 & 42.5 \\
\hline
\end{tabular}

Source: Authors' calculations 
Table 3: Model Prediction: City Housing Prices

\begin{tabular}{ccccc} 
& \multicolumn{2}{c}{ Beijing (\%) } & \multicolumn{2}{c}{ Shanghai (\%) } \\
& Data & Model & Data & Model \\
\hline \hline Avg. growth: 1998-2012 & 4.5 & 8.1 & 12.4 & 8.1 \\
Avg. growth: 1998-2007 & 2.2 & 7.3 & 11.4 & 9.5 \\
Ratio of 2012/1998 & 3.47 & 2.87 & 4.58 & 2.76 \\
Ratio of 2007/1998 & 1.67 & 1.95 & 2.75 & 2.13 \\
& & & & \\
& Success & NMSE & Success & NMSE \\
\hline \hline 1998-2012 & 0.49 & 0.05 & 0.41 & 0.16 \\
\hline
\end{tabular}

Decomposition of City Housing Prices (Percent)

\begin{tabular}{ccccc}
\multicolumn{5}{c}{ Beijing } \\
Period & Entry Fee & Land Supply & Down Payment & Productivity \\
\hline \hline $1998-2012$ & 28.8 & 31.4 & 17.9 & 21.9 \\
$1998-2002$ & 28.2 & 33.1 & 16.1 & 22.6 \\
$2003-2007$ & 27.6 & 23.6 & 21.5 & 27.3 \\
$2008-2012$ & 19.0 & 28.6 & 0.4 & 51.9 \\
\hline
\end{tabular}

Shanghai

\begin{tabular}{ccccc} 
Period & Entry Fee & Land Supply & Down Payment & Productivity \\
\hline \hline $1998-2012$ & 28.3 & 24.9 & 17.7 & 29.1 \\
$1998-2002$ & 29.0 & 29.3 & 19.5 & 22.2 \\
$2003-2007$ & 31.4 & 24.8 & 19.0 & 24.9 \\
$2008-2012$ & 12.9 & 6.7 & 1.1 & 79.4 \\
\hline
\end{tabular}

Source: Authors' calculations. 
Figure 1: Housing Price Evolution in China

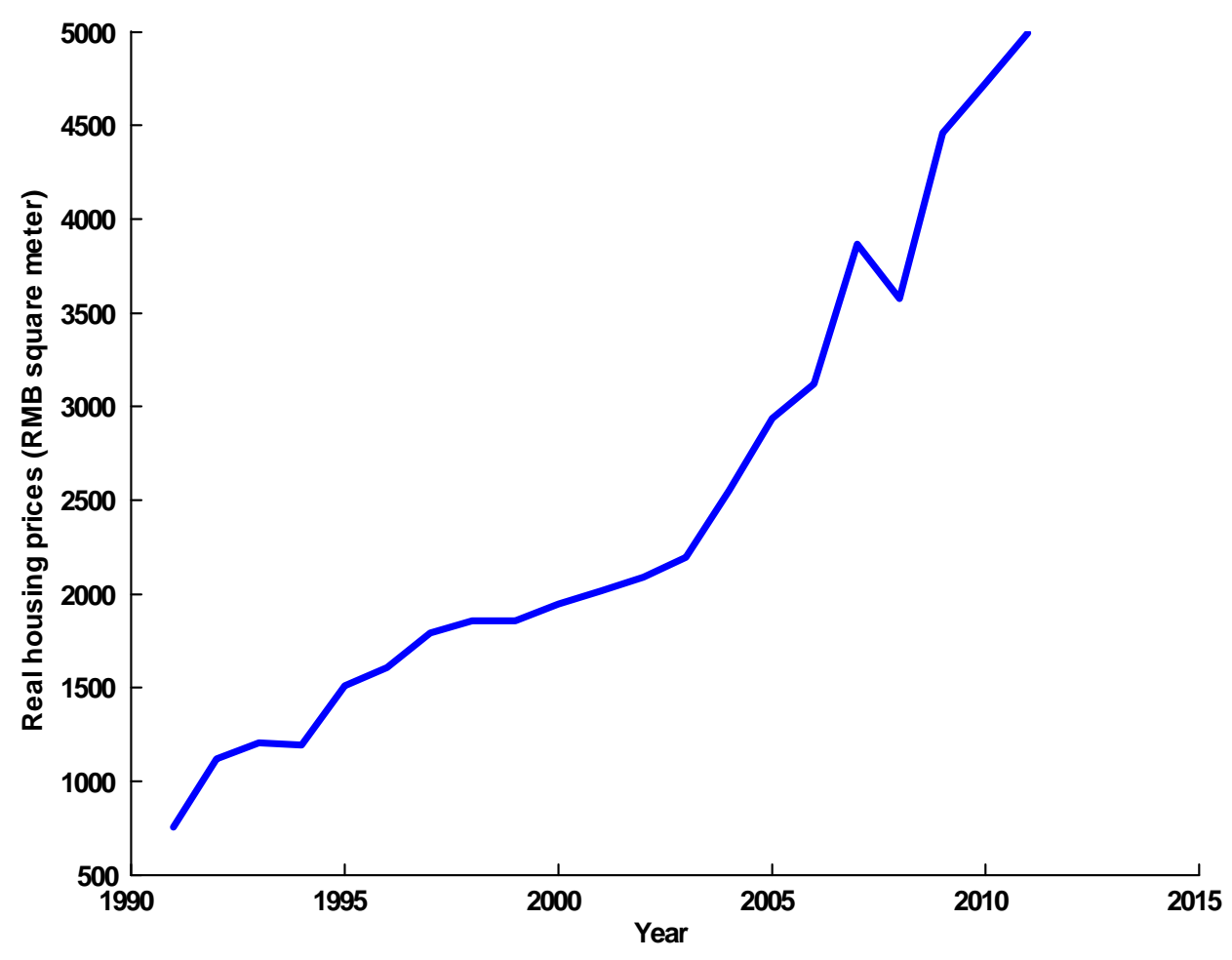

Source: National Bureau of Statistics of China. 
Figure 2: Structural Change, Migration, and Housing Price Growth in Chinese Cities
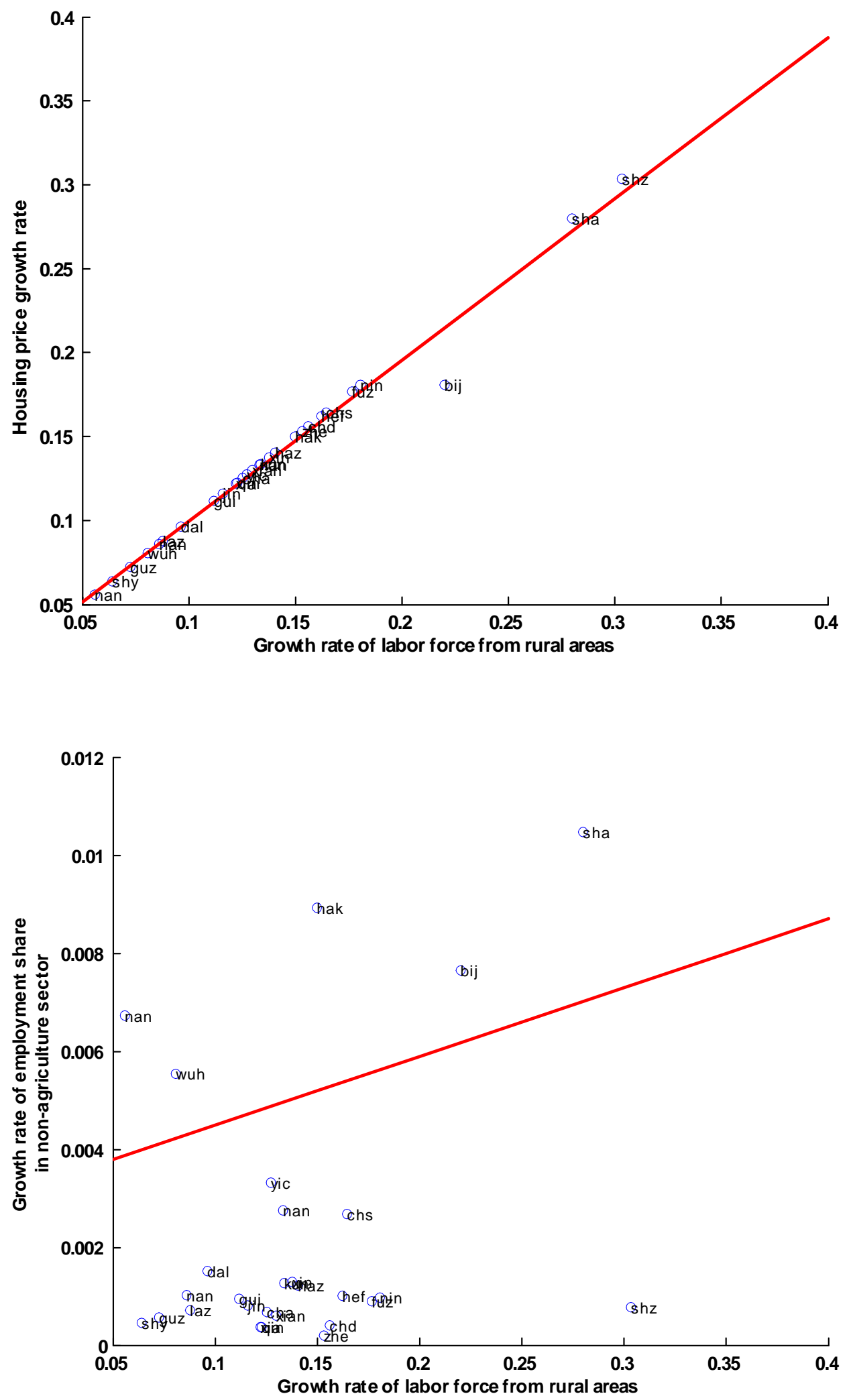

Source: National Bureau of Statistics of China. 
Figure 3: Structural Transformation/Urbanization in China

Agricultural Employment Share

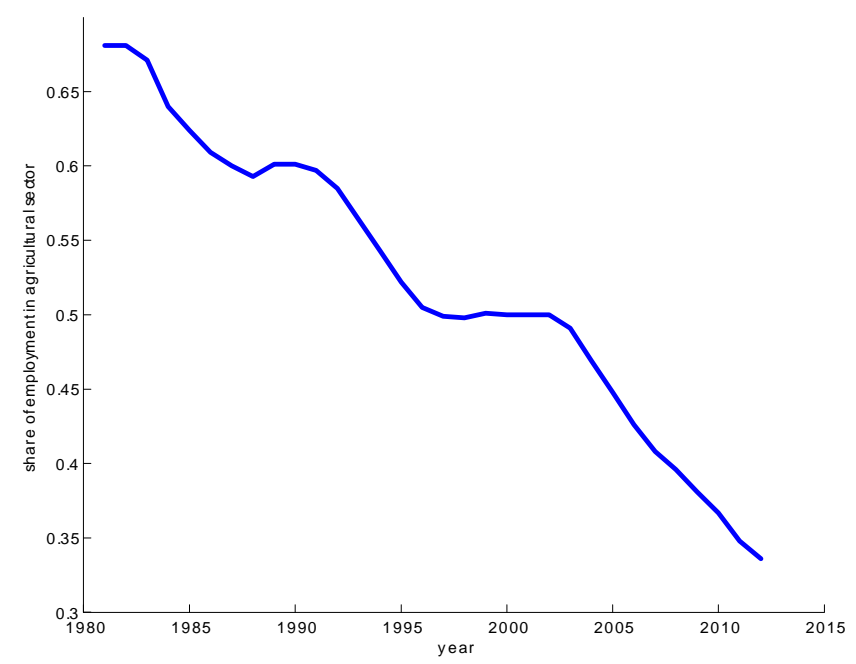

Fraction of the Urban Employment

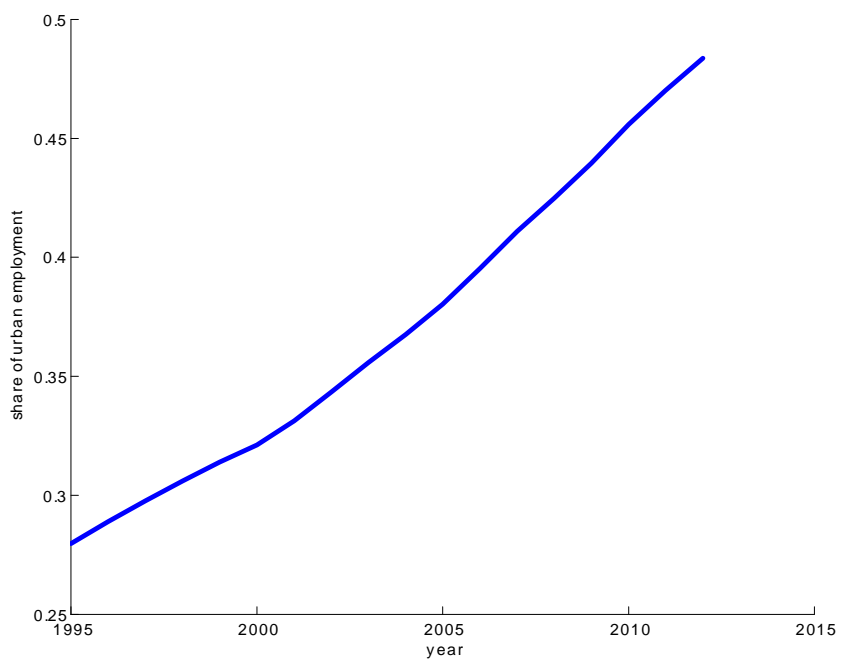

Source: National Bureau of Statistics of China. 


\section{Figure 4: Projected Series Calibration}
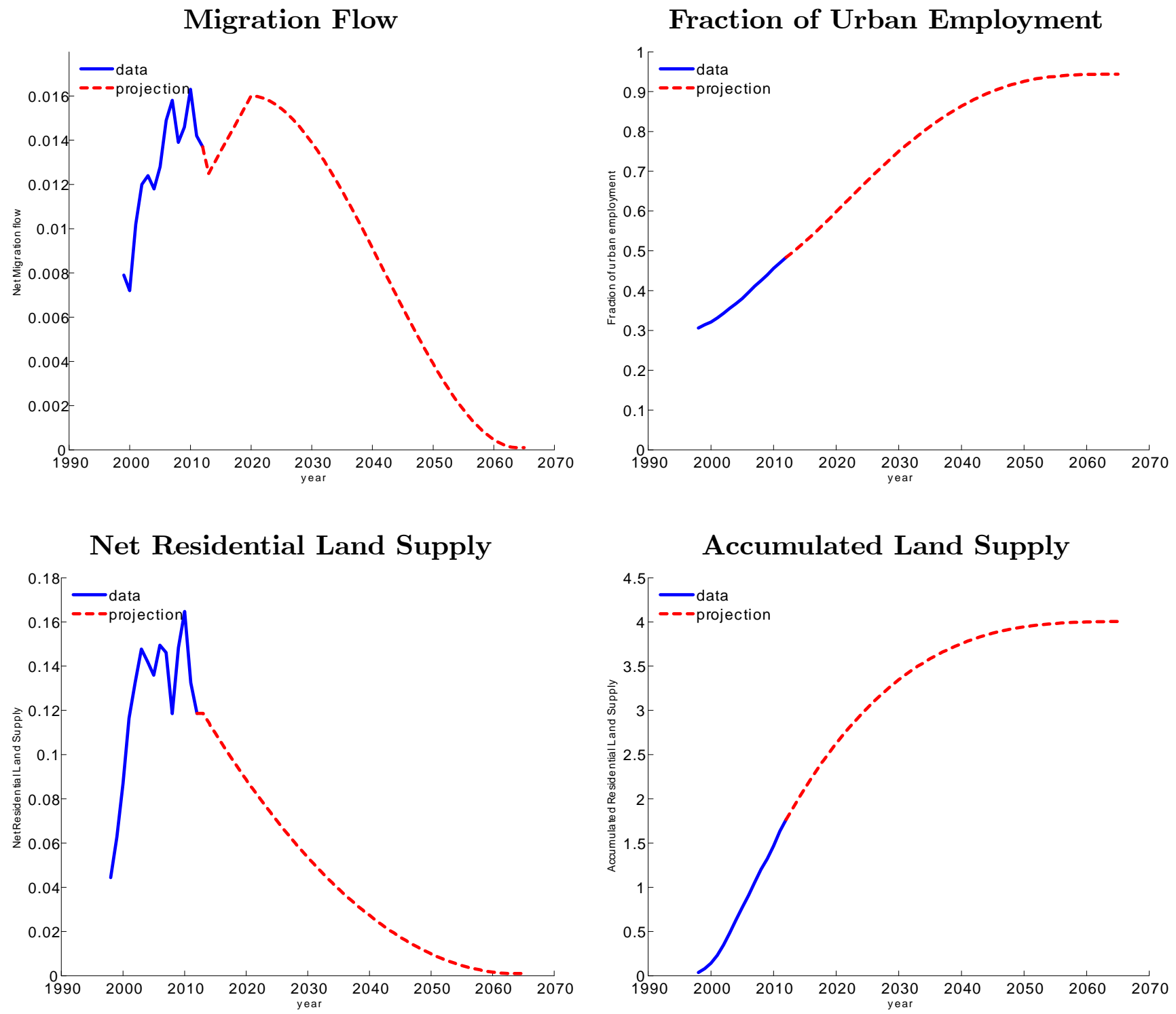

Source: National Bureau of Statistics of China and model implied data. 


\section{Figure 5: National Housing Prices}

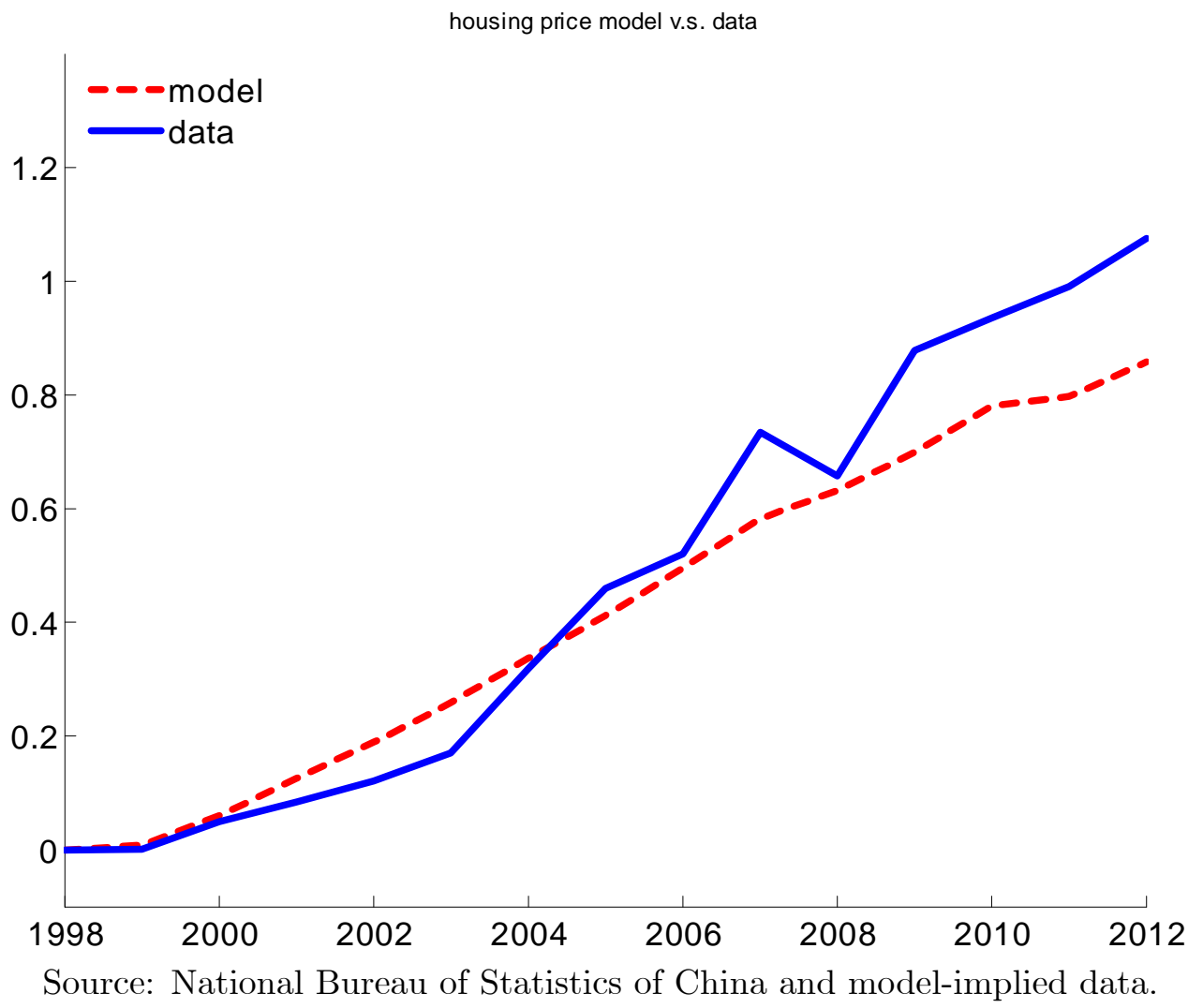


Figure 6: Evidence of Housing Prices and Residential Land Supply (Beijing and Shanghai)

\section{Housing Prices (Beijing)}

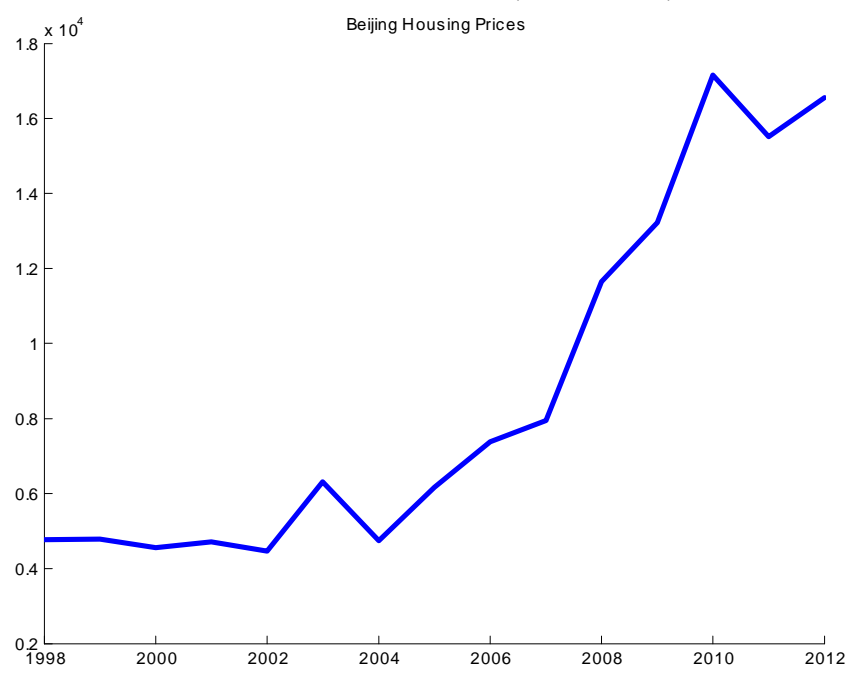

Residential Land Supply (Beijing)

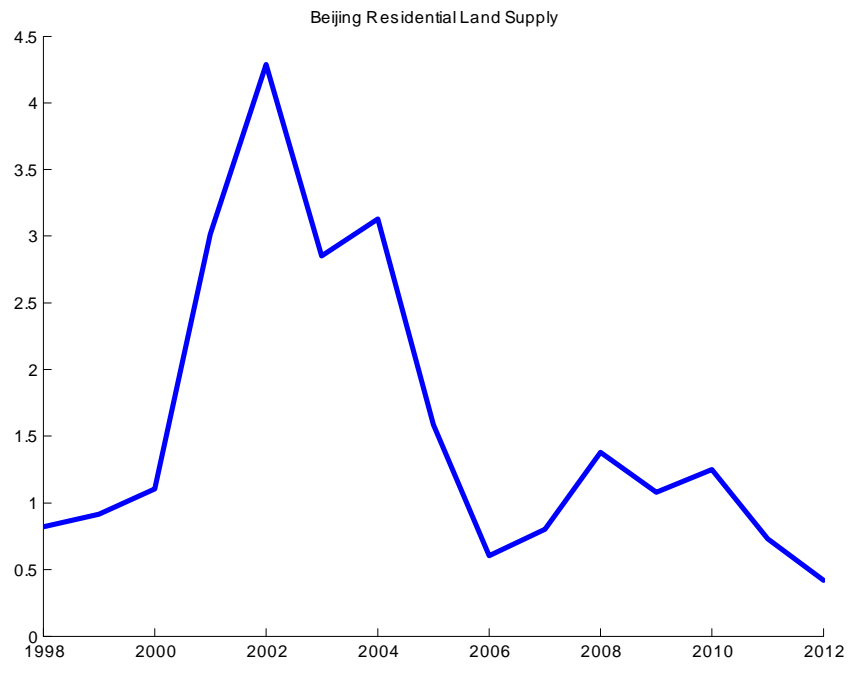

Housing Prices (Shanghai)

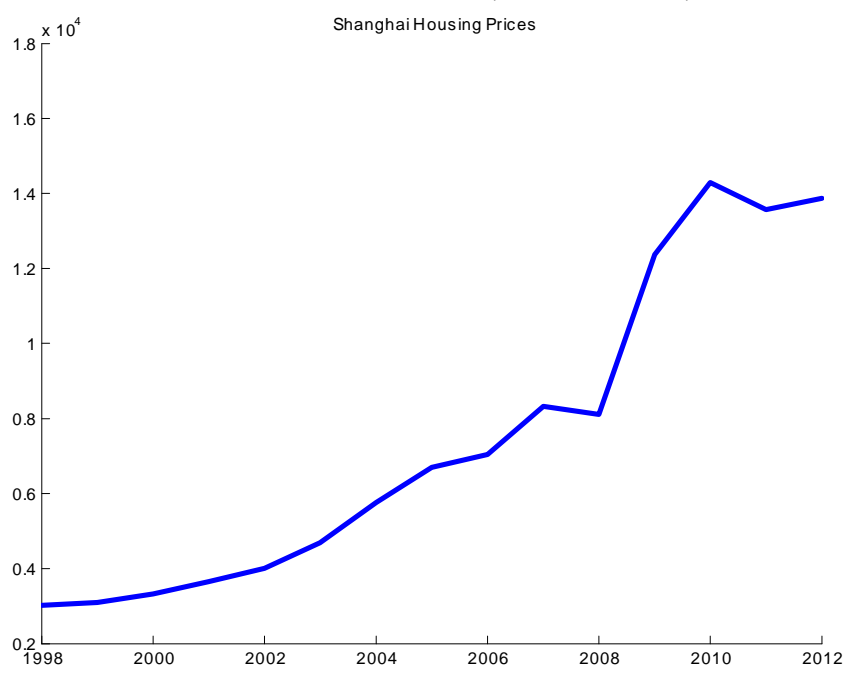

Residential Land Supply (Shanghai)

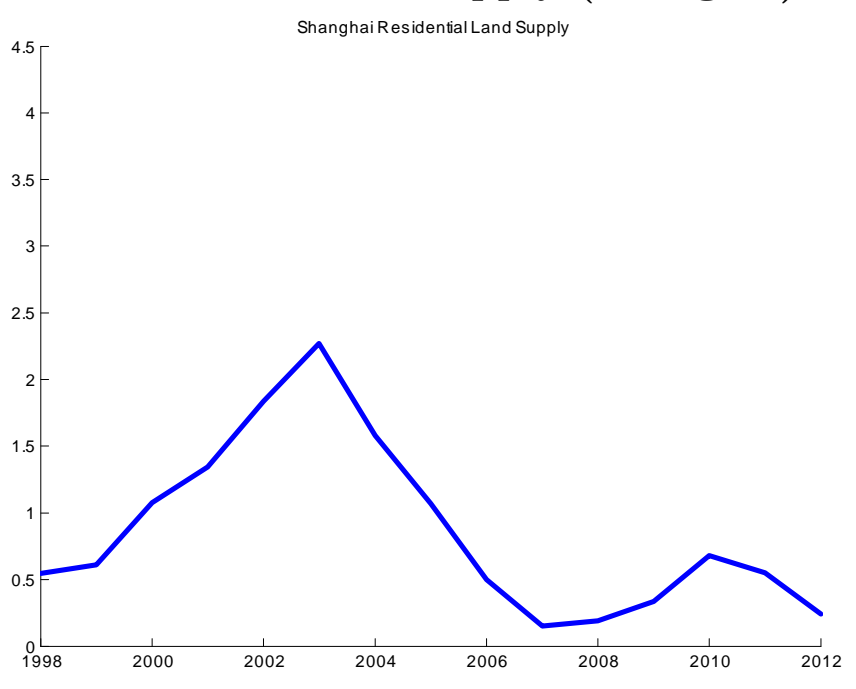

Source: National Bureau of Statistics of China 
Figure 7: Housing Prices in Beijing and Shanghai
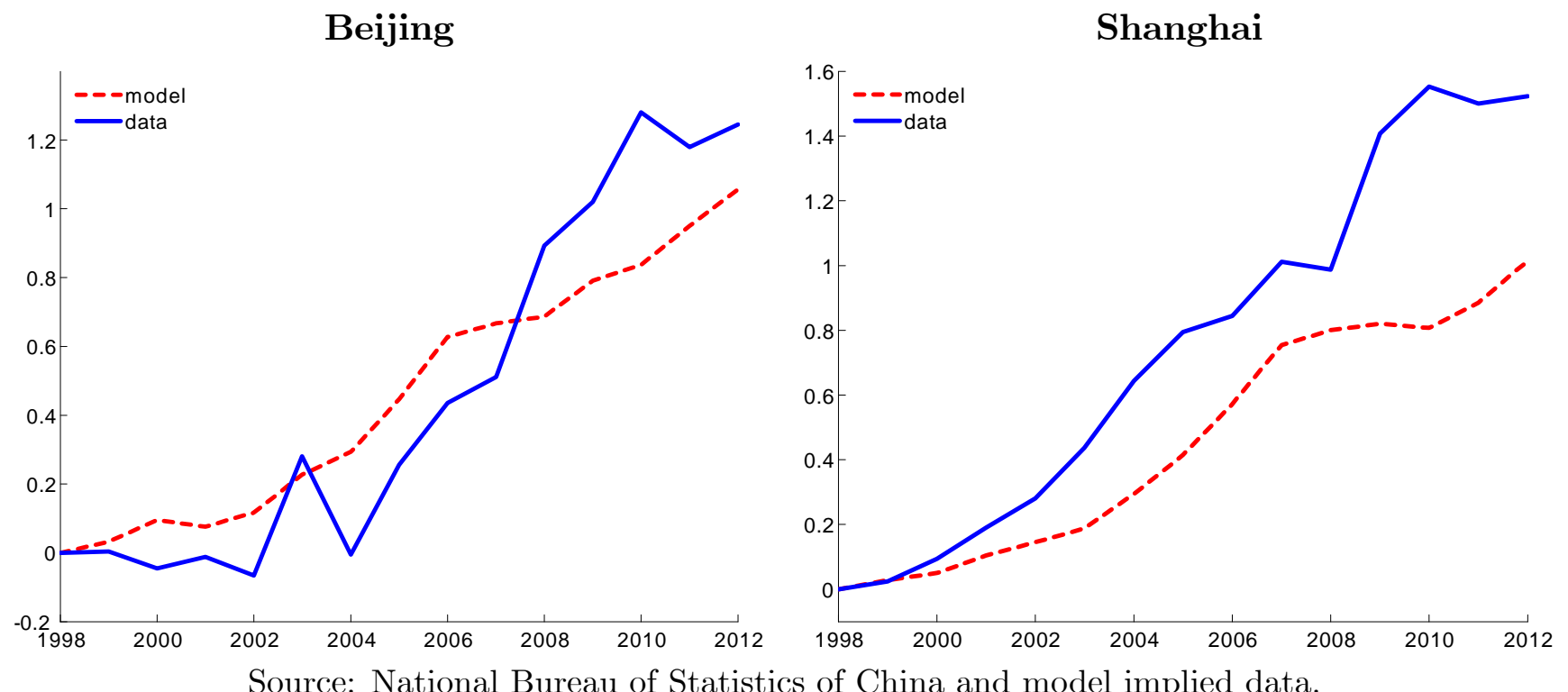

Source: National Bureau of Statistics of China and model implied data. 
Figure 8: Sensitivity Analysis of National Housing Prices)

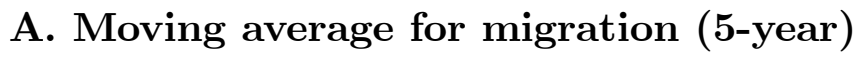

B. Pure Rental Case
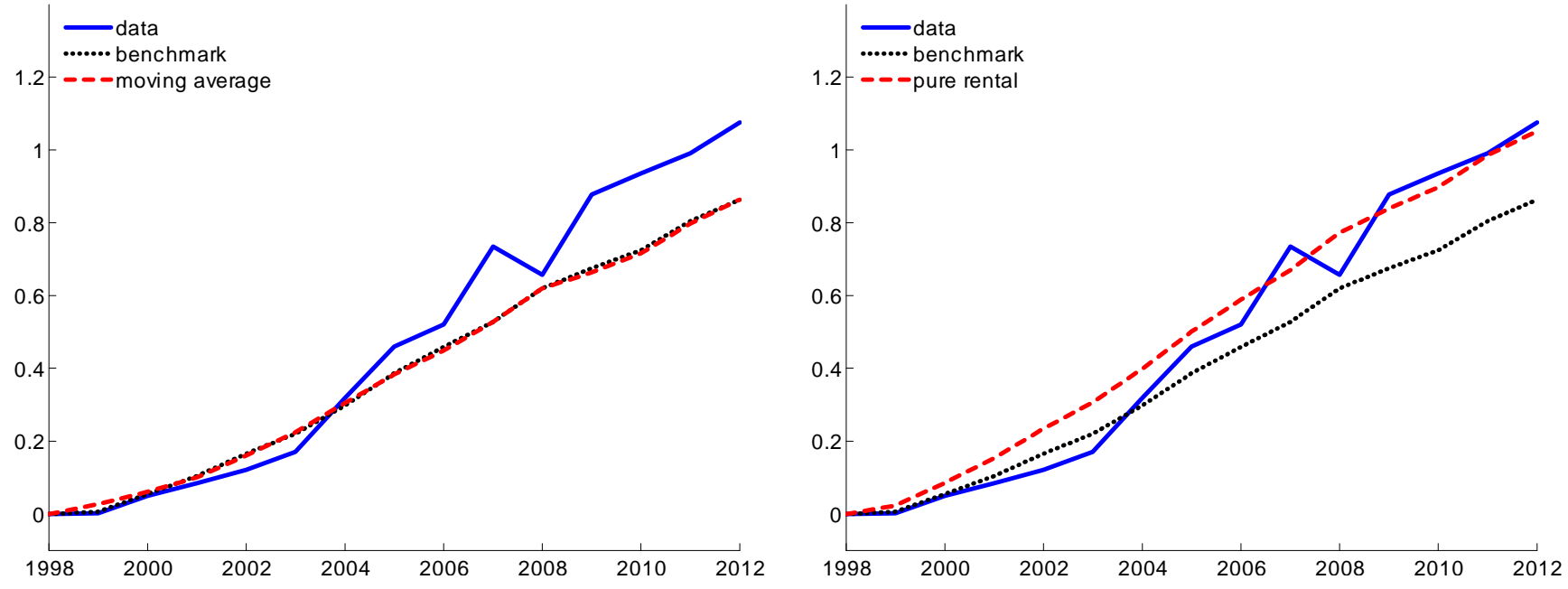

\section{Housing Quality}
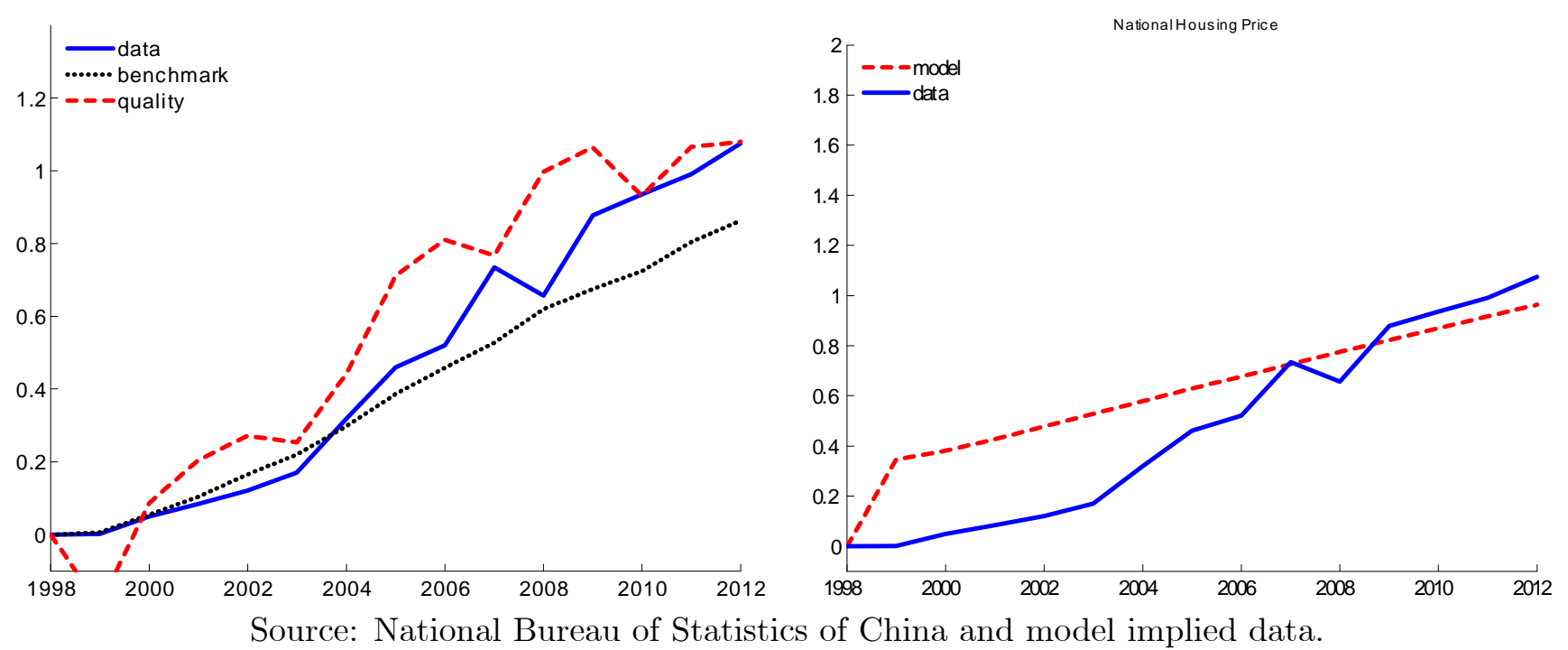
Figure 9: Matched Expenditure Shares (1998-2013)
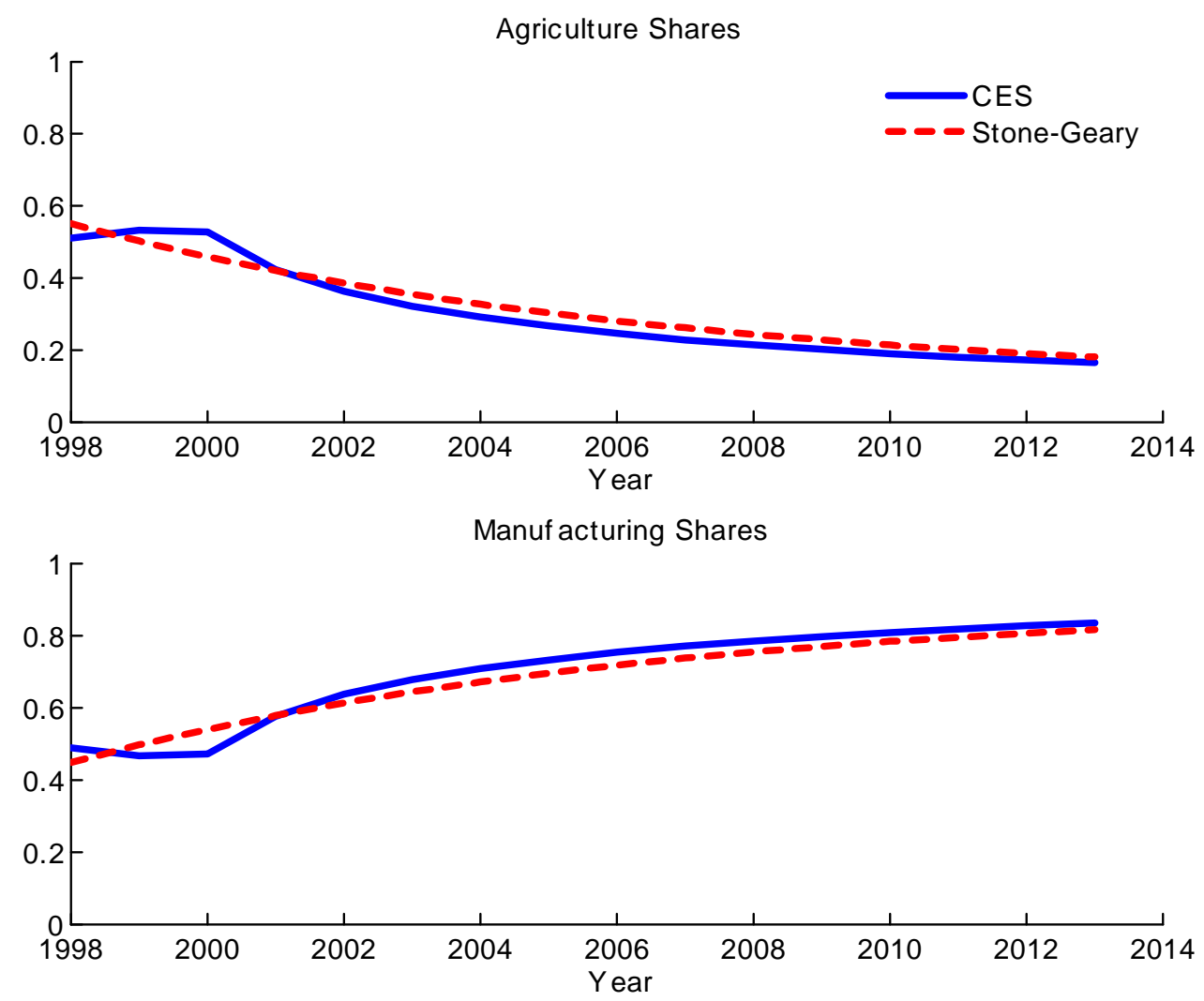

Source: National Bureau of Statistics of China and model implied data. 


\section{Appendix A: An Overview of Development in China (All Appendices Are Not Intended for Publication)}

This appendix summarizes development in China by focusing on the processes of structural transformation and urbanization and their impact on the housing market. We begin by documenting some stylized facts and then discuss the importance of migration policies and the deregulation of housing markets.

\section{MIGRATION POLICIES}

"The Third Plenary Session of the Eleventh Central Committee of the Communist Party in China" in 1978 is widely believed to be the turning point in China's development path. After this meeting, the Chinese economy began to transition from a centrally planned to a market-oriented economy. A key feature of the market economy is the introduction of incentive mechanisms and the reduction of the monopoly power of state-owned enterprises. The encouragement of entrepreneurship stimulated unprecedented technological progress in all sectors. As labor productivity in the agricultural sector improved, surplus rural labor became available for urban employment. However, migration across regions remained heavily regulated by the household registration system in China.

The individual registration system, called "hukou" in Chinese, is required by law and still in use, although it has changed significantly through the years. Each individual must have a registration record, which officially identifies him or her as a resident of an area and includes identifying information such as name, parents, spouse, and date of birth. In 1958, the Chinese government officially promulgated this system to control the movement of people between urban and rural areas. Individuals were broadly categorized as "rural" or "urban" workers. A worker seeking to move from the country to an urban area for non-agricultural work had to apply through the relevant bureaucracies. The number of workers allowed to make such moves was tightly controlled. Migrant workers needed six passes to work in provinces other than their own. People who worked outside their authorized domain or geographical area did not qualify for grain rations, employer-provided housing, or health care. There were additional controls over education, employment, marriage, and so on. Although there have been changes over time, the hukou system is widely regarded as an impediment to economic development, and removing its restrictions is often viewed as crucial for fostering the migration needed to support industrialization. Indeed, China's reform could not have begun without changes in economic institutions. China's rural-urban migration history can be divided into three stages based on changes in the central government's migration policy that began in 1978 . 
1. Steady stage (1978-1983): During this early stage of reform, all economic changes were still under probation and the key theme was slow progress. Because of the continued emphasis on agricultural self-sufficiency, most of the migration flows were within rural areas. Of the about 14 to 23 million migrants during this time, only 1 million migrated across provinces, which was less than 0.1 percent of the total population. Although agricultural productivity advanced during this period, those workers who left their farmland moved mainly to local township enterprises. This shift created a phenomenon called "leave the land without leaving home." Workers left the farm labor force but still resided in rural areas.

2. Gradual growth stage (1984-1994): As agricultural productivity continued to increase, more rural workers left the agricultural sector, and local township enterprises could not accommodate these surplus laborers. The leave-the-land-without-leaving-home mode required a breakthrough. As a result, to meet the needs of economic development, policies restricting migrants from moving from rural areas to cities were mitigated. In 1984, the General Office of the State Council published a new document on the settlement of rural migrants in urban areas, making it easier to migrate to the city. This reform of the hukou system drastically improved the employment opportunities for rural workers. Cities grew as the mantra gradually changed to "leave both land and home." Meanwhile, instead of moving mainly to small towns, as in the early 1980s, rural workers started moving to bigger cities, including megalopolises such as Beijing and Shanghai. From 1984 to 1994, rural-urban migration generally kept a steady pace. The average number of rural migrants moving across provinces increased to 3.2 million per year, three times as many as in the previous stage.

3. Highly active stage (1995-2000): Population movement in China became highly active beginning in 1995. Over the period 1995 to 2000, the total number of rural migrants moving across provinces grew from 3.5 to 10 million. Growth in this stage was the result of three important policy changes:

- Deng Xiaoping southern tour: With the world-famous speech given by Deng Xiaoping in 1992 and the reforms that followed, the Chinese economy boomed. The eastern coastal area experienced unprecedented economic growth, and a number of special economic development zones were built, which attracted many foreign enterprises and investment. This growth created more jobs in cities in these zones, inducing more workers to leave rural areas.

\section{- Abandonment of the centrally planned food and housing allocation system:} Prior to 1995, the central government generally controlled the allocation of food and housing among citizens; workers without a legal permit to live in the city were not able to obtain food and housing. Even though they could afford them because there were essentially no markets for them to trade in. The establishment of markets for basic 
living necessities such as food and housing greatly facilitated the entry of rural people into the city.

- Temporary work permits in large cities: Toward the end of the 1990s, migration accelerated as a result of policies that allowed migrants temporary permits to work in large cities. For instance, in 1997 the General Office of the State Council permitted some big cities, such as Shanghai and Guangzhou, to print "blue household registration cards" or "temporary permits" for rural workers according to the city's needs. It is estimated that in Zhejiang province, one of the richest provinces in China, the rural migrant population reached 1.9 million from 1998 to 2001. Some provinces abolished all official restrictions between rural and urban areas by declaring everyone a "citizen of that province" with equal treatment under the same set of policies. The salient feature of the rural-urban migration in this period was likely the concentration of economic development in the eastern coastal areas, which had faster economic growth and higher wages.

\section{THE DEVELOPMENT OF THE HOUSING MARKET IN CHINA}

After the 1978 Central Committee the Communist Party sessions, urban housing reforms became a major focus of the economic transformation. The central government has been very cautious in applying new reform policies in the public housing sector and has conducted out various experiments to commercialize the existing urban public housing. All land (urban and rural) is owned by the state, where developers can lease the rights to use the land from the government.

According to the 2010 Population Census, the reported statistic for the national homeownership rate in China is around 85 percent. The national average roughly captures a close to 100 percent homeownership rate in rural areas (close to 50 percent of the households surveyed) with a relatively lower rate in large cities. More specifically, the homeownership rates in the two largest cities, Beijing and Shanghai, were close to 60 percent (with several provinces above 80 percent). These numbers are substantially higher than some of the largest cities in the United States (i.e., cities like Los Angeles and New York have home ownership rates below 40 percent). In addition to a high homeownership rate, Deng, Gyourko, and Wu (2015) use the Urban Household Survey in nine provinces from 2002 to 2009 to show that most Chinese cities have a modest vacancy rate. In particular, the vacancy rate in Beijing is about 5 percent, with the highest vacancy rate in Zhejiang province at only 7.9 percent. The high homeownership and low vacancy rate are considered in designing the structure of the model.

The path of urban housing and land market reforms can be divided into three stages: 
1. Probation and experimentation stage (1978-1988): An April 1980 speech by Deng Xiaoping announced urban housing reform. He pointed out specifically that (i) urban residents should be allowed to purchase houses (old or new) and (ii) public housing rents should be adjusted in accordance with rising construction costs (which encouraged home buying rather than renting). These policies symbolized a major shift in long-standing policies for the public housing system. Following Xiaoping's directive, limited experiments were conducted in selected cities between 1980 and 1998, focused on reorganizing housing production and promoting sales of public housing to ensure a sufficient return on housing investment. These experiments included encouraging new housing sales for building costs alone, subsidizing public housing sales, and increasing public housing rents steadily each year to promote sales.

These policies, however, provided little incentive for private or other forms of housing investment. In the centrally planned economy, housing investments were provided solely by the state through a redistribution process. During economic reform, the central government tried to adopt policies to decentralize managerial power and introduce market functions into the economy. With no experience with a market economy, however, the majority of SOE became less competitive than the emerging collectively owned and private enterprises. Consequently, public housing subsidized by the central government could not keep up with the increasing demand for public housing. Although the private sector increased steadily each year, there was not enough incentive for the private sector to move toward urban housing investment because of the risk. Therefore, private investment in housing production was low and insufficient total investment in urban housing was inevitable. The market for land use is nonexistent and developers purchase the rights of use directly from the government.

2. Further urban housing reform (1988-1998): At the beginning of 1988, the central government held the first national housing reform conference in Beijing. It was agreed in that conference that housing reform could lead to great economic and social benefits and that a bigger systematic housing reform plan was necessary. The major resolutions of the conference were summarized in a document that was updated and published in 1991. This document marked a turning point in urban housing reform, from pilot tests and experiments in selected cities to implementation in all urban areas. Although there were no significant changes in the overall objectives, this was the first resolution to recognize ownership of private housing purchased from the public sector. Purchasers of public housing had two options: (i) Pay the market price and have complete ownership of the unit or (ii) pay the "standard price" (subsidized price) for partial ownership. This reform conveyed the message that the urban housing sector would eventually rely on market forces rather than central planning.

Although a less than fully privatized housing market had been established, most participants in that market at that time were employers, not individual buyers. With different interests and more independent policies, employers and local governments purchased houses 
and then provided them to their employees at rents substantially below market rates. Thus, the overwhelming majority of urban residents lived in public housing that was also tied to their employment. As a consequence, there was less incentive for urban residents to purchase housing units.

3. Current stage of urban housing policies (1998-present): In July 1998, the new State Council adjusted the housing policy and issued an official document. One major change was the termination of material distribution of housing at the end of 1998, which was completely replaced by monetary distribution. According to the new plan, no newly built units were to be allotted. The new policy symbolized the end of the existing public housing system, with the ultimate goal of fully commercializing the housing market. Nonetheless, the government continued to provide cheap-rent housing for the lowest-income households, but the average floor space per person could not exceed 60 percent of the local average. Individuals who did not qualify for these government programs had to purchase or rent houses in the private market. During this period public land auctions were institutionalized in 2002 and became widespread across all cities. By August 31, 2004, all urban land leasing sales were required to be through public auctions with Internet posting to the public. Local land bureaus remained in charge of annual allocation of land plots for development, the associated regulations (including the floor area ratios), and the types and reservation prices for auctions.

In response to the financial tsunami, the Chinese government implemented two additional policies with the objective of cooling off the housing boom. The main regulatory changes were the restriction on owning multiple housing units (including regulations that required a minimum down payment of 60 percent), mortgage restrictions on nonlocal households, and sales restrictions in second- and third-tier cities to only local or migrant households. Other housing policies aimed at slowing housing price growth included higher property tax rates in Shanghai and Chongqing as well as building and running public rental housing. Such tightened housing policy was recently reverted during the first quarter of 2015 to revive the sluggish growth of the housing market.

\section{Appendix B: Technical Companion}

consol Mortgage: The consol fixed-rate mortgage (FRM) considered in our paper possesses the following properties:

Proposition 1: Consol FRM has zero amortization, $b_{t}=b_{t+1}$.

Proof: A mortgage payment contains two parts: the amortization and the interest payment. Amortization is defined as the difference between today's debt and tomorrow's debt:

$$
\begin{aligned}
m_{t} & =a_{t}+i_{t}, \\
a_{t} & =b_{t}-b_{t+1} .
\end{aligned}
$$


The debt level in period 0 is $b_{0}=(1-\phi) q_{0} h$, and the interest payment in period 1 is

$$
i_{1}=\left(\frac{1}{\beta}-1\right) b_{0} .
$$

Assume the mortgage payment decreases at a constant rate $g$ over time. The absence of arbitrage condition implies

$$
(1-\phi) q_{0} h=\sum_{t=1}^{\infty} \beta^{t} d_{1}(1-g)^{t} .
$$

We can solve $d_{1}$ as follows:

$$
d_{1}=(1-\phi) q_{0} h \frac{1-\beta(1-g)}{\beta(1-g)} .
$$

Therefore, amortization in period 1 can be derived as

$$
a_{1}=d_{1}-i_{1}=g(1-\phi) q_{0} h
$$

Under a constant debt repayment scheme, amortization is zero.

Proposition 2: The down payment constraint is always binding.

Proof: Consider parameter values $\left\{A_{t}^{m}\right\}$ such that there "reverse migrations" from the city to the rural area are not optimal. In this case, the relevant optimization problem becomes

$$
\begin{gathered}
V_{t}^{C}\left(\epsilon, b_{\tau}\right)=\max U\left(c_{t}^{m}, c_{t}^{f}, h_{t}\right)+\beta V_{t+1}^{C}\left(\epsilon, b_{\tau}\right), \\
\text { s.t. } \quad p_{t} c_{t}^{f}+c_{t}^{m}+b_{\tau} r^{*}=w_{t}^{m} .
\end{gathered}
$$

Rewriting the optimization problem sequentially gives

$$
\begin{gathered}
\max \sum_{t=0}^{\infty} \beta^{t} U\left(c_{\tau+t}^{m}, c_{\tau+t}^{f}, h_{\tau}\right), \\
\text { s.t. } \quad c_{\tau}^{m}+p_{\tau} c_{\tau}^{f}+q_{\tau} h_{\tau}=w_{\tau}^{m}+b_{\tau}, \\
c_{t+\tau}^{m}+p_{t+\tau} c_{t+\tau}^{f}+b_{\tau} r^{*}=w_{t+\tau}^{m}, \quad \forall t>1, \\
b_{\tau} \leq(1-\phi) q_{\tau} h_{\tau} .
\end{gathered}
$$

The Lagrangian has the form

$$
\begin{aligned}
& \mathcal{L}=U\left(c_{\tau}^{m}, c_{\tau}^{f}, h_{\tau}\right)+\lambda_{0}\left(w_{\tau}^{m}+b_{\tau}-c_{\tau}^{m}-p_{\tau} c_{\tau}^{f}-q_{\tau} h_{\tau}\right)+ \\
& \quad \sum_{t=1}^{\infty} \beta^{t}\left[U\left(c_{\tau+t}^{m}, c_{\tau+t}^{f}, h_{\tau}\right)+\lambda_{t}\left(w_{t+\tau}^{m}-c_{t+\tau}^{m}-p_{t+\tau} c_{t+\tau}^{f}-b_{\tau} r^{*}\right)+\gamma\left((1-\phi) q_{\tau} h_{\tau}-b_{\tau}\right) .\right.
\end{aligned}
$$


First-order conditions with respect to $\left\{c_{t+\tau}^{m}, c_{t+\tau}^{f}\right\}$ and $b_{\tau}$ give the following:

$$
\begin{aligned}
c_{t+\tau}^{m} & : U_{1}^{\prime}\left(c_{\tau+t}^{m}, c_{\tau+t}^{f}, h_{\tau}\right)=\lambda_{t}, \\
h_{\tau} & : U_{3}^{\prime}\left(c_{\tau}^{m}, c_{\tau}^{f}, h_{\tau}\right)-\lambda_{0} q_{\tau}+\sum_{t=1}^{\infty} \beta^{t} U_{3}^{\prime}\left(c_{\tau+t}^{m}, c_{\tau+t}^{f}, h_{\tau}\right)+\gamma(1-\phi) q_{\tau}=0, \\
b_{\tau} & : \lambda_{0}-\sum_{t=1}^{\infty} \beta^{t} \lambda_{t} r^{*}-\gamma=0 .
\end{aligned}
$$

When $\gamma>0$, the borrowing constraint will be binding. Collecting the terms gives

$$
\gamma=\lambda_{0}-\sum_{t=1}^{\infty} \beta^{t} \lambda_{t} r^{*}=U_{1}^{\prime}\left(c_{\tau}^{m}, c_{\tau}^{f}, h_{\tau}\right)\left[1-r^{*} \sum_{t=1}^{\infty} \beta^{t} \frac{U_{1}^{\prime}\left(c_{\tau+t}^{m}, c_{\tau+t}^{f}, h_{\tau}\right)}{U_{1}^{\prime}\left(c_{\tau}^{m}, c_{\tau}^{f}, h_{\tau}\right)}\right]
$$

Therefore, $\gamma$ is positive as long as the utility function is strictly increasing, weakly concave in the consumption component, and the discount factor satisfies $\beta \leq \frac{1}{1+r^{*}}$. 


\section{Appendix C: Data Sources and Definitions}

Employment and Population: The source for the urban and agricultural employment data come from China Statistical Yearbook. The statistics cover all agencies and units providing employment services and job centers. The scope of statistics on private enterprises and self-employed individuals covers the whole country, which includes 31 provinces, autonomous regions and municipalities directly under the central government. The number of employed people in urban areas does not include those who had left their working units and kept their labor contract/employment relation unchanged since 1998. The share of agriculture in GDP is from primary industry measures.

Migration Flow: The migration charts in Figure 2 are obtained from the City Statistical Yearbook. The labor force from rural areas is measured as the number of workers holding agricultural hukou.

Housing Prices: The data source is China Statistical Yearbook. Nominal housing prices are calculated using total sales of residential buildings divided by the floor space of residential buildings. Real housing prices are calculated by deflating nominal housing prices by the consumer price index in urban areas.

Residential Land Supply: The data source is China Statistical Yearbook. The flow of residential land supply is land purchased in the current year. The measure of total urban land area is constructed from data on area of land used for urban construction.

City-Level Data: Housing price data for both Beijing and Shanghai are from China Statistical Yearbook 1998-2012 and are deflated using the consumer price index in each city. The simulated housing price is based on a calibrated multiple-city model, which mimics several stylized facts of the Chinese economy as well as migration patterns into each city. The flow of residential land supply is land purchased in the current year. We use the area of land used for urban construction to measure the total urban land area for both cities. 